TO WHOM IT MAY CONCERN:

I, SANOY MARANGOS- FROST, authorize the National Library of Canada to microfilm the following pages/graphs/charts or appendix out of the attached thesis as is: 144 , $16-124$, though they may not be legible when reproduced. For reference, a bound copy of the thesis will be available at the University of Toronto's Science \& Medicine Library

Sularcuef trust

Signature

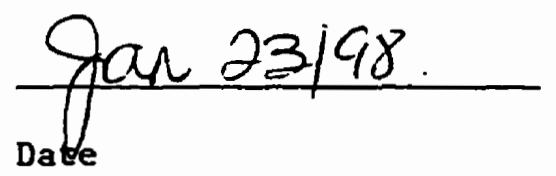





\title{
PSYCHIATRIC NURSES' THOUGHTS AND FEELINGS ABOUT RESTRAINT USE: \\ A DECISION DILEMMA
}

\author{
by
}

Sandy Marangos-Frost

A thesis submitted in conformity with the requirements

for the degree of Master of Science

Graduate Department of Nursing Science

University of Toronto

(C) Copyright by Sandy Marangos-Frost 1998 
The author has granted a nonexclusive licence allowing the National Library of Canada to reproduce, loan, distribute or sell copies of this thesis in microform, paper or electronic formats.
L'auteur a accordé une licence non exclusive permettant à la Bibliothèque nationale du Canada de reproduire, prêter, distribuer ou vendre des copies de cette thèse sous la forme de microfiche/film, de reproduction sur papier ou sur format électronique.

L'auteur conserve la propriété du droit d'auteur qui protège cette thèse. $\mathrm{Ni}$ la thèse ni des extraits substantiels de celle-ci ne doivent être imprimés ou autrement reproduits sans son autorisation. 
Psychiatric Nurses' Thoughts and Feelings about Restraint Use:

A Decision Dilemma

Sandy Marangos-Frost

Master of Science, 1998

Graduate Department of Nursing Science

University of Toronto

\section{Abstract}

This ethnographic qualitative study concerned nurses' thoughts and feelings regarding restraint use in the psychiatric setting. The theoretical approach which guided this study was the work of Etzioni (1992) which focuses on the role of normative-affective factors in decision making. The analysis of the thoughts and feelings of the six nurses interviewed revealed that the restraint situation represented a decision dilemma. The decision dilemma was captured by four supporting themes: the framing of the situation: the potential for imminent harm, the unsuccessful search for alternatives to physical restraints, the conflicted nurse, and the conditions of restraint. The findings contribute insights about why restraints continue to be used. Also, there are implications for restraint use in the psychiatric setting, future research, and understanding restraint use in light of decision making theory. 


\section{Acknowledgements}

This thesis represents one of the most stimulating and challenging accomplishments of my life. It was not, however, without the undying and unconditional support of many that this study was ever completed.

First and foremost to be recognized are my husband Tim and my son Patrick. They loved, supported and encouraged me through both the best and the most difficult times. They made my laugh, kept me from crying and reminded me to stop and enjoy life.

To my parents who instilled in me a sense of selfconfidence. They taught me to believe that I could achieve all that I desire if I was prepared to work hard and stay true to my self. This belief has sustained me through this experience.

To my closest friends, Elizabeth, Louise and Lena who endured countless hours of my complaining only to respond by supporting and encouraging me. They helped me keep the balance in my life especially by organizing our getaways to Lena's haven in Muskoka and asking only that I be present.

To my thesis supervisor, Donna Wells, my mentor and coach. She continually challenged me to broaden my thinking and helped me to achieve a potential that I was not even aware 
I was capable of achieving. Her confidence in me, my skills and my abilities sustained me through the roughest times. Donna approached her role as a supervisor with a sense of compassion and with conviction.

To my committee members, Barbara Johnson and Beth McCay, who impressed my with their knowledge and their critical thinking abilities. I could count on Barb and Beth to raise poignant points that enhanced my perspective and this thesis.

I have a tremendous amount of respect and admiration for my entire committee. Donna, Barbara and Beth challenged me when needed, supported me when needed and always worked together in a collegial manner. I consider myself fortunate to have had the experience of working with them.

Finally, to my boss, Mr. Uwe Marshner, a very special person. Uwe supported me in every way possible so that I could continue with my education in spite of a demanding job. His kindness and compassion were instrumental in enabling me to manage a demanding career, a family as well as my educational pursuits.

I often believed that this thesis would never reach completion. I have had to cope with some of the most challenging obstacles and exciting life events along the way. 
My determination and the tremendous support of the people who are important to me have helped me get to where I am today. 
Abstract . . . . . . . . . . . $\quad$ ii

Acknowledgements . . . . . . . . . . . . . iii

\section{CHAPTER 1}

Background . . . . . . . . . 1

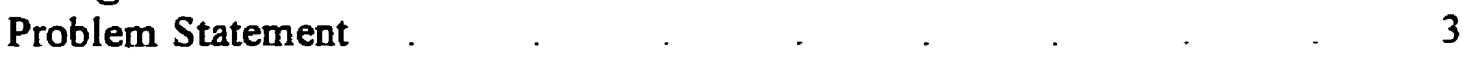

Review of Related Literature . $\quad$. $\quad$. $\quad$. $\quad$. 3

Patient-Related Characteristics . . . . . 4

Socio-demographic characteristics . . . . 4

Patient behaviours . . . . . . 5

Facility or Organizational Factors . $\quad$. $\quad$. $\quad 8$

Staff-Related Influences . . . . . . . 99

Staff perceptions of patient behaviour a . . $\quad$. 9

Emotional reactions of staff and restraint use. . . II

Literature Review Summary . . . . . . . 14

Study Purpose $\quad . \quad$. $\quad . \quad . \quad . \quad . \quad . \quad 15$

Conceptual Framework . . . . . . . . . 16

Research Questions . . . . . . . . . . 20

\section{CHAPTER 2}

Design and Methods . $\quad . \quad$. $\quad . \quad . \quad 22$

Research Approach . $\quad$. . . . $\quad 22$

The Researcher's Perspective . . . . . . . . 23

Access to the Setting and to Subjects . . . . 24

Sampling and Sample Size . . . . . . . 25

Data Collection Techniques . $\quad$. $\quad$. . . $\quad$. 26

Ethical Considerations $\quad . \quad$. $\quad . \quad$. $\quad . \quad 33$

Data Analysis Strategies. . . . . . . 35

Data Organization: creating a coding system . . 36

Data interpretation: identifying themes, patterns

Methodological Rigor. $\quad . \quad$. $\quad . \quad . \quad . \quad 39$

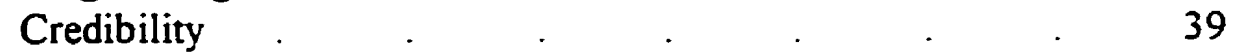

Transferability . . . . . . . . 40

Dependability . $\quad . \quad$. $\quad$. $\quad$. $\quad$. $\quad$. 41

Confirmability . . . . . . . . . 41 


\section{CHAPTER 3}

The Study Findings . $\quad$. $\quad$. $\quad . \quad$. 43

Descriptions of the Study Participants, Restraint Incidents and the Study Site. $\quad$. $\quad$. $\quad$. $\quad$. $\quad$. $\quad . \quad 43$

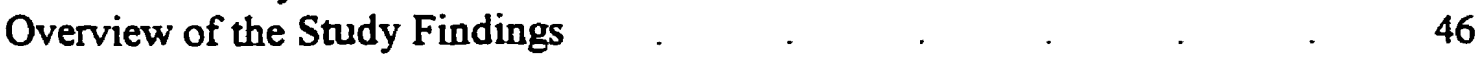

Elaboration of the Study Findings . $\quad$. $\quad$. $\quad . \quad$. $\quad$. 47

Framing of the Situation: The Potential for Imminent Harm. $\quad 47$

The Unsuccessful Search for Alternatives to Physical Restraint. $\quad 59$

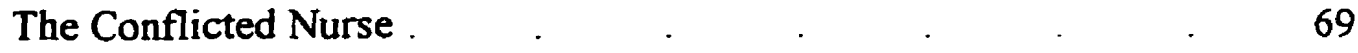

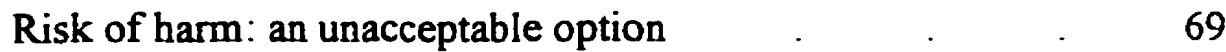

Physical restraints: an unwelcome option . . . . $\quad 74$

The emotional impact of restraint use on nurses . $\quad 78$

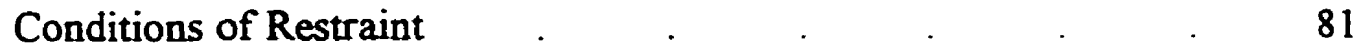

The composition of the inpatient population at the time . $\quad 81$

The facility's constant care policy . . . $\quad 86$

The attitude of management and physicians . $\quad$. $\quad 87$

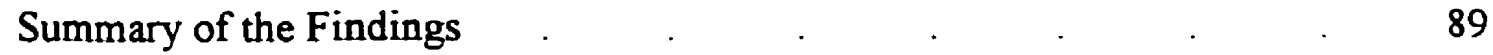

\section{CHAPTER 4}

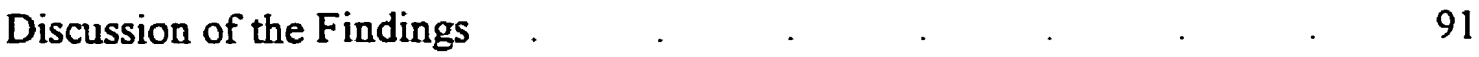

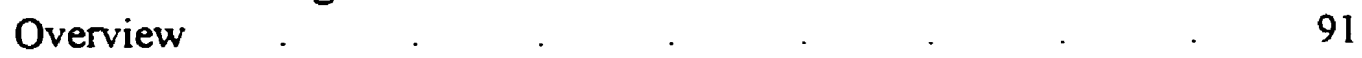

Emergent Themes and the Existing Literature . . . $\quad 92$

Emergent Themes and Conceptual Framework $\quad$. $\quad$. $\quad 99$

\section{CHAPTER 5}

Summary, Limitations, and Recommendations . $\quad$. . . . $\quad$. 104

Summary . $\quad . \quad$. $\quad . \quad$. . . . $\quad . \quad 104$

Limitations and Challenges . . . . . $\quad 105$

Recommendations for Research, Theory, and Clinical Practice . $\quad 106$

Research . . . . . . . . . 106

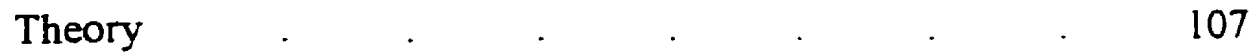

Clinical practice $\quad . \quad . \quad . \quad . \quad . \quad . \quad . \quad 67$

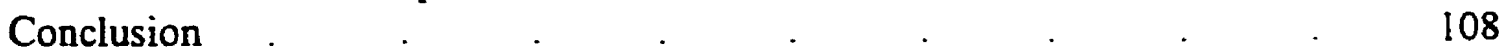

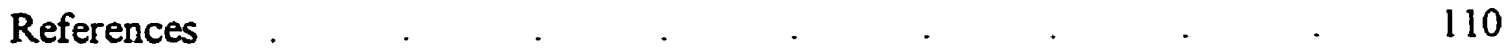




\section{Appendices}

Appendix A: Letter of Orientation for Potential Study Participants

Appendix B: Explanation of Study to Potential Study Participants

Appendix C: Interview Consent Form

Appendix D: Socio-Demographic Information

Appendix E: Interview Guide

Appendix F: Contact Summary Sheet

Appendix G: Characteristics of the Restrained Patients and Incident Information

Table

Table 1: Socio-demographic Characteristics of the Nurses

Interviewed 
CHAPTER 1

Background

In the Province of Ontario, restraint of a psychiatric inpatient is governed by the Mental Health Act. According to this act, restraint means "to place under control when necessary to prevent serious bodily harm to a patient or to another person" (Chapter 262, section 1, 1988, 1996). Research and my clinical practice indicated that there was dramatic variation in the incidence of physical restraint in psychiatric inpatient settings. In the past decade or so, rates at which patients were restrained on at least one occasion while admitted to a psychiatric inpatient unit across hospital settings have been reported to range from $2.8 \%-84 \%$ (Cappenter, Hannon, McCleery, \& Wanderling, 1988; Crenshaw \& Francis, 1995; Okin, 1985; Phillips \& Nasr, 1983; Ray \& Rappaport, 1995; Sheridan, Henrion, Robinson, \& Baxter, 1990; Soloff, 1979; Soloff, Gutheil, \& Wexler, 1985; Way \& Banks, 1990). According to Ray and Rappaport, this variation tended to be unrelated to differences in patient characteristics, hospital settings or facility policy governing restraint use. 
A key to understanding the continued use of physical restraint in psychiatry may lie in understanding the influence of staff-related factors on the decision to restrain. This decision most often rests in the hands of nurses (Yarmesch \& Sheafor, 1984) and is guided by the provisions of the Mental Health Act. Nurses are required to make a judgement about a patient's potential to cause serious bodily harm to themselves or to others. This judgement may be influenced by a multitude of factors including nurses' perceptions of patient behaviour as violent or potentially violent and nurses' emotional reactions to violent and potentially violent patients. Violence has been described as interactional, influenced by the dynamics of the patient and by the dynamics of the nurse caring for the patient (Roper \& Anderson, 1991). It has been reported, as well as evident in my clinical practice, that nurses experience fear, anxiety, helplessness and hopelessness when caring for potentially violent and violent patients (Coulson et al., 1985, 1986; DiFabio, 1981; Dubin 1989; Roper \& Anderson, 1990). Nurses' emotional reactions may influence nurses' decisions to use physical restraints, but this has not been a specific focus of study. 
Problem Statement

Restraint use remains prevalent on psychiatric inpatient units across hospital settings. Findings from investigations examining the relationship between patient-related factors and facility-related factors have not sufficiently explained the continued use of restraints. Studies of staff-related factors and restraint use have contributed to an understanding of the interactional dynamic of violence but have not contributed to any specific conclusions regarding the influence of the thoughts and feelings of nurses while in restraint situations on the decision to restrain. Learning more about the thoughts and feelings nurses experience in restraint situations may assist in understanding the continued use of physical restraints in psychiatry.

\section{Review of Related Literature}

A computerized review of the literature on physical restraint and seclusion in psychiatry revealed a plethora of references to empirical studies and theoretical literature on the subject of physical restraint in psychiatry. Key words that guided the search were: physical restraint, emergency psychiatry, psychiatric nursing, violence in psychiatric settings, management of aggressive behaviour and clinical 
decision making. The literature selected for review focused on physical restraint in the psychiatric setting according to three categories. These were: (a) patient-related

characteristics, (b) facility or organizational factors, and (c) staff-related influences. The following presentation of the literature review is organized according to these categories.

Ratient-Related Characteristics

Socio-demographic characteristics. Empirical studies have examined the relationship between age, sex, and diagnosis of the patient and the use of physical restraint (Betemps, Somoza, Bouncher, 1993; Carpenter et al., 1988; Mattson \& Sacks, 1978; Okin, 1985; Phillips \& Nasr, 1983; Sheridan et al., 1990; Soloff, 1978, 1979; Soloff et al., 1985; Way \& Banks, 1990). The majority of studies that examined restraint use were conducted in a variety of psychiatric inpatient settings and reported that males under the age of 34 were the patients most often placed in physical restraint. This finding was consistent across sites, for the most part, despite differences in sample size, hospital location (i.e, city, suburban and small town), and patient population. Way and Banks, however, used a logit model of analysis due to their 
large sample $(n=24,000)$. They reported that females between the ages of 26-35 years had the highest probability of being physically restrained. In the study by Sheridan et al., which was conducted in a veterans hospital serving a mostly older, male population, the mean age of a sample of 73 restrained patients was 53 years old, 97\% of whom were male.

Studies conducted in 82 veterans hospitals, as well as, in 23 state hospitals across the United States of America, reported that schizophrenia was the diagnosis most frequently associated with the use of physical restraint (Betemps et al., 1993; Carpenter et al., 1988; Sheridan et al., 1990; Soloff et al., 1985; Steele, 1993; Way \& Banks, 1990). Although this finding was consistent across studies, this finding should be interpreted with caution given the different diagnostic procedures which may have been used in each study. Betemps et al. were the only investigators to have described how patient diagnoses were determined.

Ratient behaviours. In investigations conducted in a variety of hospital settings, patient behaviours precipitating physical restraint were categorized in one of two ways. Some investigators classified patient behaviours as either violent or non-violent (Okin, 1985; Soloff, 1979), while others 
categorized behaviour on the basis of whether it was related to events internal to the patient (psychotic) or events external to the patient (non-psychotic) (Betemps et al.,1993; Phillips \& Nasr, 1983; Sheridan et al., 1990; Soloff, 1978, 1983).

The category of non-violent patient behaviours, which encompassed a range of behaviours such as agitation, anxiety and hostility, accounted for more restraint use than did actual acts of violence (Okin 1985; Soloff, 1979). Studies using the classification of events internal to the patient (psychotic) and external to the patient (non-psychotic), reported that psychosis per se did not, in and of itself, result in increased restraint use (Phillips \& Nasr, 1983; Sheridan et al., 1990; Soloff, 1978, 1983). Events external to the patient included behaviours disruptive to the milieu such as violation of community and administrative limits, conflict with staff over smoking rules, and patient elopement from the unit. Phillips and Nasr reported that psychotic patients exhibited more non-violent types of behaviours as compared to non-psychotic patients, but it was the behaviour rather than the psychosis on which the decision to restrain was based. Findings of Johnson, Martin, Guha and Montgomery (1995) 
supported Phillips and Nasr. In interviews with patients diagnosed with a thought disorder, Johnson et al. reported that patients described events external to them, not psychotic symptoms, as precipitants of aggressive incidents.

Most of the above studies, with the exception of Sheridan et al. (1990), and Johnson et al. (1995) were based on descriptions of patient behaviours which were taken from patients' medical records. Phillips and Nasr (1983) suggested that retrospective studies of restraint use are disadvantaged by the lack of opportunity to assess patient behaviour as it occurred at the time of restraint.

The conclusions of studies examining patient-related characteristics indicated that a pattern of restraint use exists in which young male patients with a diagnosis of schizophrenia were most often restrained and that non-violent behaviour was the leading precipitant of restraint use. Although a pattern of restraint use exists, these results only partially explain the use of physical restraints. The results would be more meaningful if the context of each restraint episode was examined. 


\section{Eacility or organizational Factors}

Unit organizational structure and unit values or ideologies have been highlighted as significant factors influencing patient behaviours, including violence, as well as restraint use on psychiatric inpatient units (Katz \& Kirkland, 1990; Morrison, 1990; Philiips \& Nasr, 1983). In Katz and Kirkland's study involving extensive observation of staff and patients, as well as in-depth interviews with staff members working on six different units, unit organizational and social structures were reported to influence patient behaviour, particularly the level of violence. Violence-prone units, as referred to by staff and by the investigators, were described as generally lacking in routine for both patients and staff. Staff relationships were characterized by a lack of trust, and there were infrequent interactions between staff and patients. The peaceful units, on the other hand, were characterized by unit schedules that were adhered to and staff relationships were described as trusting.

Morrison (1990), in an exploratory study using participant observation and in-depth interviews with health care professionals from three psychiatric units in an urban general hospital, concluded that the unit philosophy 
influenced restraint use. The particular unit philosophy described by Morrison was based on the medical-model in that all patient behaviours were considered symptoms of illness to be managed. Violent behaviour was treated as a symptom of illness to be controlled through the use of physical restraint. Also, nurses spoke of receiving recognition from management when patients in their care maintained control even if this was achieved through the use of restraints. Morrison concluded that the medical-model ideology influenced staff to such a degree that new staff were encouraged to control patients' behaviour and to view physical restraint as an acceptable means of achieving this control.

The findings related to the role of facility factors suggested that facility factors influenced restraint practices. These factors, therefore, should be considered along with patient-related characteristics in order to better understand the continued use of physical restraints in inpatient psychiatric units.

\section{Staff-Related Influences}

Staff perceptions of patient behaviour. Staff members' perceptions of patients as difficult and behaviour as violent have been demonstrated to have influenced the use of 
restrictive measures such as restraints (Coulson et al., 1985, 1986; Gallop \& Wynn, 1987; Morrison, 1993; Okin, 1985). Coulson et al., and Gallop and Wynn, observed that certain patient behaviours were identified as difficult by the assigned mental health professionals. Investigations by these authors identified patient behaviours perceived by professionals as difficult, the feelings aroused in the professionals caring for this difficult population, and the high rate at which restrictive measures were utilized with this patient group. Those patients who were most often restrained demonstrated intense unpredictable affect, impulsivity, anxiety, violence, and threatening behaviour, all of which aroused feelings of defeat, lack of control, and pressure in staff caring for them.

Nurses with psychiatric experience who were employed in hospital settings and who were required to manage violent or potentially violent behaviour daily have been reported to vary greatly in their perceptions of the severity of violent patient behaviour as compared to nurses with no such experience (Morrison, 1993). It has been suggested that these varying perceptions of violent patient behaviour may explain the high rate of restraint use in some state hospitals in the 
United States (Okin, 1985). Okin discovered variation in the incidence of restraint use across seven state hospitals which had similar admission and discharge policies, operated under identical regulations, and had similar patterns of seclusion and restraint. In this study, hospitals with high rates of restraint use had low rates of violence. This could not be explained by okin on the basis of patient characteristics. He suggested that nurses in the study settings perceived behaviour as potentially violent and restrained patients on this basis. The low rates of actual violence were speculated as being due to the fact that patients were restrained before they had the opportunity to act violently.

Emotional reactions of staff and restraint use. The reactions of mental health professionals to potentially violent and violent patients have been speculated as influencing the choice of staff intervention (Dubin, 1989; Felthous, 1984; Roper \& Anderson, 1991). Both Dubin (1989) and Felthous (1984) hypothesized that psychiatrists felt anxious and frightened by patients who had the potential to become violent, and that they may have responded in authoritarian ways, become punitive, and used restrictive measures that unwittingly provoked patients or gave patients the impression 
that they were expected to behave violently. They further suggested that violent patients most often felt overwhelmed by feelings of helplessness and fear of others; authoritarian responses by staff may have compounded such feelings.

Dubin (1989), Felthous (1984), and Lion and Pasternak (1973) labelled the responses of psychiatrists as countertransference reactions and psychological defenses. Countertransference reactions are those emotional responses of the therapist toward the patient (Lion \& Pasternak, 1973). The psychological defenses identified included denial and projection. Roper and Anderson (1991), who interviewed and observed nurses working in inpatient settings, reported similar findings. The emotional responses most commonly associated with nurses in their interactions and relationships with potentially violent patients included anxiety, fear, hopelessness, and helplessness. As well, Roper and Anderson reported that nurses distanced themselves from violent patients, downplayed the potential for violence, and either misinterpreted or exaggerated patients' behaviours.

Coulson et al. (1985, 1986) and DiFabio (1981) reported on the emotional reactions of nurses and other professionals working with psychiatric inpatients. These reactions included 
feelings of fear, anxiety, helplessness, hopelessness and defeat. Roper and Anderson (1991), as well as Coulson et al., and DiFabio strongly suggested that these emotional reactions to potentially violent and violent patients may have confounded the management of violence by virtue of nurses: (a) using physical restraint to control behaviour, (b) distancing themselves from patients, and (c) handling patients punitively. This conclusion was also suggested by Dubin (1989) and Felthous (1984) in their descriptions of clinical experiences of psychiatrists' reactions to potentially violent and violent patients.

Interacting with potentially violent patients may give rise to staff members' own feelings of anger, which can unconsciously be projected towards patients (Dubin, 1989; Felthous, 1984). Anger in these situations has been related to the fear and helplessness staff feel as a result of the lack of patient progress or the potential for anger to be directed at staff. This defensive reaction may influence staff to prematurely use restrictive measures.

Although these studies have addressed nurses' perceptions of patients as difficult and their behaviour as violent, as well as the emotional reactions of mental health professionals 
to potentially violent and violent patients, these studies did not examine the influence of these perceptions and reactions on restraint decisions. Neither did they elicit information from staff themselves who had recently been involved in a restraint situation. While the results have begun to shed light on the ongoing practice of restraint use, there still remains a gap in understanding the continued use of physical restraint. The study was intended to fill this gap.

\section{Literature Review Summary}

Empirical evidence exists indicating that young, male patients diagnosed with schizophrenia were the patients who were most frequently placed in physical restraints while an inpatient of a psychiatric unit. A range of non-violent behaviour, such as patient agitation, patient hostility, potential elopement from the unit, and conflict with staff accounted for greater restraint use than did actual acts of violence. The organizational structure of inpatient psychiatric units has been reported to influence levels of violence on the unit. Unit philosophies have been found to: (a) play a role in influencing nurses' perceptions of patient behaviour as violent or potentially violent; and (b) sanction 
the use of restrictive measures such as physical restraint to control patient behaviour.

Nurses working in inpatient settings varied in their perceptions of the severity of violent behaviour. This variation may have implications for understanding the ongoing use of physical restraints. Nurses also experience certain emotional reactions to potentially violent and violent patients. It has been speculated that these reactions influence the use of restrictive measures. Although restraint use has been extensively studied, little is known from the literature about why restraints continue to be used in the psychiatric setting. Learning about nurses' thoughts and feelings regarding restraint use may shed light on why restraints continue to be used.

\section{Study Purpose}

The purpose of this study was to learn more about nurses' thoughts and feelings in response to situations which resulted in the physical restraint of a psychiatric inpatient, and the influence of these thoughts and feelings on the decision to restrain. A secondary purpose of the study was to expand our understanding of why professionals continue to use restraints in psychiatric inpatient settings. 
Conceptual Framework

Approaches to decision making have been classified as normative or descriptive (Baron, 1994). Normative models are concerned with rational choice and logical decision-making processes aimed at achieving an ideal or its approximation. Conversely, descriptive models are concerned with people's beliefs and preferences as they are, not as they should be and explain why and how decisions may deviate from predictions generated by rational or normative models. Below is a discussion of why a descriptive model, rather than a normative model based on rational choice, was selected as the framework for this investigation.

Rational choice theories, in their purest form, have the following underlying assumptions about individuals: (a) they are motivated by self-interest, (b) they act out of rationality, (c) they behave independently of each other, (d) they behave in an effort to maximize options, (e) they define their values in terms of their preferences and ( $f$ ) they, rather than an organization, are the unit of analysis for decision making (Zey, 1992). Rational choice theories also assume that organizations function rationally and efficiently. 
Rational choice models generally follow a common, multiple-step process (Zey, 1992). This process includes some form of information gathering regarding the problem and the alternatives for resolving it, weighing the risks and benefits associated with each alternative, selecting an alternative and implementing the choice. A rational choice process has been described as superior because it is prudent and absent of emotional influences (Baron, 1994). Nonetheless, this process is limited. It is rarely possible to have knowledge of all the alternatives and their consequences. The same problem may be viewed differently and the lack of recognition of these differences may limit the alternatives selected, as well as limit the evaluation of risks and benefits (Zey). Behaviour predicted by rational choice models should be consistent but in reality it is not.

In reality, most people do not make decisions guided only by rational choice (Baron, 1994). Significant decisions may evoke anxiety and strain for some and this can provide a constructive basis for behaviour and decision making (Etzioni, 1992). Etzioni has suggested that emotions and values do not distort the decision-making process and should be granted a proper place in decision making. Values and emotions influence 
every aspect of decision making and, if recognized, can account for variances (Etzioni, 1992).

Etzioni (1992) posits a descriptive model of decision making based on a view of human nature that contrasts with the view inherent in the assumptions underlying rational choice theories. Specifically, Etzioni's position is that decision makers rely on value commitments and emotional involvements and they make decisions in the context of moral commitments, affect and social factors. Furthermore, Etzioni holds that decision making is based less on information gathering and more on behaving in ways consistent with internalized morals, values, and emotions. These normative-affective factors influence the options considered, and the choice made. Etzioni believes that rational choice models are influenced by normative-affective factors. That is, these factors shape what information is gathered, the way it is processed, the inferences drawn, the options considered and the decision itself (Etzioni, p.9I). Etzioni's approach requires lateral thinking, involving jumping to conclusions, whereas the logical-empirical approach involves a vertical sequential process that is prescriptive in nature. 
Normative-affective factors influence decision making in two significant ways. First, there is the exclusion of the consideration of particular options as a result of the influence of internalized morals, values or emotions. Second, a process of "infusion" (Etzioni 1992, p.95) occurs in which options are ranked but the ranking is not based on a numeric assignment of utility or probability. Affect and values are prominent. Affect or emotion, depending on the degree, is seen as either limiting or liberating. "Socialized emotions" (p. 100) rather than "raw emotion" (p. 100) ensure that more than just rational choice is considered. Specifically, there is consideration of the primacy of ends over means and ethical options in the process of deciding. Emotions can influence the interpretation of the situation, motivate the mobilization of resources to resolve the situation, foster peak performance by inducing a state of arousal needed for action, and can communicate information to others. Normative values, such as equality, justice, and freedom may be internalized and influence the decision maker's perceptions and actions. According to Etzioni, both affect and normative values should be treated as significant and distinct from logical-empirical 
considerations and should not simply be superimposed on rational choice models.

In view of Etzioni's (1992) descriptive approach to decision making, the study focused on nurses' thoughts and feelings about a situation which resulted in the restraint of an inpatient in a psychiatric setting. It was believed that nurses' descriptions of their thoughts and feelings would contribute to insights about the influence of normativeaffective factors on the decision to use physical restraints.

\section{Research Questions}

The primary aim of this investigation was to learn about nurses' thoughts and feelings in situations resulting in the restraint of a patient in a psychiatric setting, and the influence of these thoughts and feelings on nurses' decisions to restrain. Another objective of the study was to further understand why professionals continue to use restraints in the psychiatric setting.

The research questions were:

1. How do nurses describe or frame situations involving the application of physical restraints to an inpatient in a psychiatric setting? 
2. What thoughts and feelings do nurses report having experienced when participating in the decision to physically restrain an inpatient in a psychiatric setting?

3. How do these thoughts and feelings influence nurses' decisions to use physical restraints on an inpatient in a psychiatric setting? 
CHAPTER 2

Design and Methods

\section{Research Approach}

The study was based on an ethnographic design in order to learn (a) how nurses described or framed situations involving the application of physical restraints, (b) what thoughts and feelings nurses reported experiencing in these situations, and (c) how these thoughts and feelings influenced the decision to use physical restraints.

Ethnography is explained by spradley (1979) as being a way of learning about people, not a study of people.

Ethnography is a centuries old approach that began as a way of describing cultures through a researcher's intense participation in the Iives of people native to the culture (Vidich \& Lyman, 1994). According to Vidich and Lyman, current thinking defines ethnography in the broadest sense as "the science devoted to describing ways of life of humankind" (p. 25). Ethnography is not simply concerned with the activities of others; it allows access to multiple realities through the collection of empirical data about people in specific situations (Spradley, 1979). It is concerned with the meaning behind the actions and events in which people engage. 
Researchers learn about people by participating in their culture and in their lives.

Understanding behaviour necessitates gaining access to peoples' changing interpretations of stimuli and the meanings associated with them (Hammersley \& Atkinson, 1983). Meanings are expressed either in language or through actions, and these meanings organize people's behaviour, and assist them to understand themselves, others and the world they live in (Spradley, 1979) .

This investigation was concerned with the thoughts and feelings of nurses involved in restraint situations. It was about understanding their decisions to restrain in terms of (a) how they described or framed the restraint situation, (b) what thoughts and feelings they reported experiencing and (c) how these thoughts and feelings influenced nurses' decisions to restrain.

\section{The Researcher's Perspective}

My perception of the decision to physically restrain inpatients was based on my clinical experience as a nurse working in psychiatry. From my perspective, it is a difficult and highly emotional experience for nurses that is not well understood. In the clinical setting, nurses have expressed 
feelings of fear, anxiety, and helplessness in situations involving the restraint of a patient, especially when patients are repeatedly restrained. I believe that the decision is influenced by a number of factors that are not fully understood by nurses. It was not my intention, however, to evaluate nurses' decisions to use restraints.

\section{Access to the setting and to subjects}

The research site was the psychiatric inpatient unit at a community hospital in North York. Initial contact was made with the inpatient Unit Manager and the Director of Nursing Practice whose role included chairing the hospital's research committee. This committee reviewed the research proposal after approval of the proposal was granted from the office of Research Services at the University of Toronto. Following approval of the study proposal, a meeting was held with the Unit Manager to provide her with a written and verbal introduction to the study. The Unit Manager assisted with the identification of potential subjects by using a letter of orientation which briefly described the study (See Appendix A). The Unit Manager forwarded the names of potential participants to the researcher only after nurses read the letter of orientation and agreed to meet with me. The 
investigator then contacted the individual subjects and arranged to meet them at a convenient time and place. At that time, the study was fully described to the nurse (see Appendix B).

\section{Sampling and sample size}

Following a restraint episode, the unit manager approached one of the nurses involved and informed them of the study. The unit manager ascertained the nurse's interest in learning more about the study and would forward their name to the researcher. The investigator then arranged to meet with the nurse and provided her with a written and verbal explanation of the study, offered her an opportunity to ask questions, and invited the nurse to participate in the study. After having read the written explanation of the study, and having discussed the study with me individually, the nurse was asked to sign the written consent to be interviewed (see Appendix C). A total of six nurses agreed to participate. Two of the six nurses interviewed were involved in the same restraint episode and the other four nurses interviewed were involved in different restraint episodes. Consequently, data were collected in relation to several restraint situations, and from several different nurses. 
It is customary in qualitative research to study in-depth a small number of people in their context (Miles \& Huberman, 1994; Sandelowski, 1995). In this investigation, involving a single setting, in-depth descriptions were sought about nurses' thoughts and feelings as experienced in situations involving the physical restraint of an inpatient in a psychiatric setting. How these thoughts and feelings influenced nurses' decisions to use restraints was also explored. A purposive sample of 10-12 subjects was hoped for; however, restraint use during the study period fell below the reported average of two incidents per month. Six nurses were interviewed during a seven-month period.

\section{Data Collection Techniques}

The primary data collection tool was the ethnographic interview with nurses who had been involved in a situation resulting in the physical restraint of inpatients in a psychiatric unit. The other source of data was the sociodemographic information provided by each nurse interviewed. These data included the participant's age, sex, years working in psychiatry, history of assault by the restrained patient or by any psychiatric inpatient, formal training in the management of aggressive behaviour, and the status of the 
nurse's relationship to the restrained patient at the time of the incident. These details about the sample allowed for descriptions which enable readers to determine if the findings may be transferable to their sites. A socio-demographic data sheet was given to each nurse to complete at the beginning of the interview (See Appendix D).

Prior to initiating the interviews, the study was explained in detail and consent was obtained. The written consent included the participant's consent to audio-tape the interview. At this time informants were reassured that their decision to restrain was not being judged. This time prior to the actual interview along with the time spent explaining the study was helpful in establishing a rapport with informants.

The interview was based on three important elements in ethnographic interviewing: explicit purpose, ethnographic explanations, and ethnographic questions (see Appendix E) (Spradley, 1979). First, it was important to make the purpose of the ethnographic interview explicit. As suggested by Spradley (1979), this required repeated explanation. It was necessary because the aim was to learn about the meaning of an event to the informant as described in their own words. What informants chose to speak of and the language they used in the 
interview provided the key to learning from, rather than leaning about, nurses' thoughts and feelings in restraint situations. In the introduction to the interview, as well as throughout the interview, nurses were asked to use their own language and to provide as detailed a description as possible of a specific and recent restraint situation in which they participated.

The second important element in ethnographic interviews are the "ethnographic explanations" (Spradley, 1979, p.59). There are five different types of explanations. The first involves a description of the purpose of the study. The process by which the study was explained has been described above. The second type describes any recordings that may be made (Spradley, 1979). Audio taping of the interviews was explained to informants as necessary in order to capture a verbatim account, which is essential to ethnographic research. It was also explained that I would be taking notes to assist me in keeping track of ideas that arise during the interview. These explanations were provided in several ways to ensure that the informants understood the purpose of the interview, the reason for the audio-taping, and that their decision to restrain was not in question. 
The third kind of explanation are the "native language" explanations. It was important that informants did not simply express their general opinion of restraint use. The one question used in all of the interviews, which was intended to stimulate the use of "native language", was:

"Describe the most recent restraint situation in which you were involved as if you were speaking to a nurse you work with."

A fourth type of ethnographic explanation is of the interview itself. It was important that informants understood that the interview was going to be different from a friendly conversation in which there is a mutual exchange of information, opinions, and experiences. As a researcher, I explained to the nurses that I would be asking few questions and sharing little, if any, information.

The final type of ethnographic explanation concerns the explanation of the types of questions asked in an ethnographic interview. The questions were designed to stimulate informants to provide detailed descriptions of a restraint episode and the thoughts and feelings they experienced while involved in the situation. The interview questions were developed in 
accordance with the three basic types of ethnographic questions.

The third important element in ethnographic interviewing is the interview questions (Spradley, 1979). Descriptive questions, the first type of ethnographic question, provide a means of collecting a sample of the language of the informant (Spradley, 1979). In this study, nurses were asked to describe a recent restraint situation as though he or she were speaking to a colleague. They also were asked to focus on their thoughts and feelings during the restraint situation, "Describe the thoughts and feelings you recall experiencing during the most recent restraint situation in which you participated."

This question was repeated frequently as nurses had some difficulty describing, or were hesitant to describe, the thoughts and feelings they recalled experiencing during the situation. It was important to keep the informants focused on the thoughts and feelings they experienced during the restraint situation. In instances in which the nurse denied feeling anything or indicated that she perceived her feelings to be somehow unimportant, the question was restated as: 
"Describe the feelings you think other nurses may experience in restraint situations."

This descriptive question encouraged the discussion of feelings.

Structured questions are a second type of ethnographic question (Spradley, 1979). Answers to structured questions enable the investigator to understand how subjects organize their knowledge. Examples of structured questions used in this investigation included:

"1. Walk me through the situation as it occurred.

2. What stood out in this situation for you?

3. Describe the behaviour and actions of the patient in the situation prior to the application of the restraints."

A final type of ethnographic question involves contrast. These questions enable the investigator to discover the meaning of terms used by the informants. How these meanings are elicited, however, is no simple process. Spradley (1979) cautions novice ethnographers not to ask informants to "tell me what you mean" or "can you define that term". These questions convey a lack of understanding and informants may feel that they are not being clear or they do not understand 
the question. Uncovering meanings through the use of contrasts in language is achieved in three ways that encourage the informant to explain terms, phrases, or concepts by using them differently. One way to achieve this is for the researcher to plead "cultural ignorance" (p. 61) and encourage the informant to view the investigator as naive. This became necessary when the study informants used terminology unfamiliar to the researcher, the researcher asked:

"1. Is that how other nurses would describe that?

2. Can you use that same word in a different sentence?" This was done to ensure that the meaning intended by the informant was uncovered rather than risking the researcher injecting her own interpretation of the term, or possibly misinterpreting the informant's intended meaning.

Pausing, another technique, indicates interest on the part of the researcher. A third technique involves restating what has been said, which will indicate active listening on the part of the researcher rather than a lack of understanding. Both pausing and restating proved to be valuable techniques used by this investigator. Pausing gave informants an opportunity to think about what they were about to say as the researcher kept silent. Restating was also 
valuable in ensuring that I did not impose my own meanings or interpretations on what the nurse was describing.

The researcher conducted all of the interviews. Each interview transcript was dated and labelled by a code identifiable only by myself and stored in a safe place. Researcher memos were written that captured my impressions as they arose with each interview experience and throughout the investigation (Spradley, 1979). Contact summary sheets were completed after each interview was transcribed (Miles \& Huberman, 1994). The contact summary sheet included some focusing or summarizing questions about each of the interviews (see Appendix F) .

\section{Ethical Considerations}

Several steps were taken to ensure that the researcher Eulfilled the responsibility to protect the rights of subjects (Burns \& Grove, 1993). Before data collection began, approval for the project was granted by the Office of Research Services of the University of Toronto and the hospital's Research Committee. Nurses involved in the restraint of a psychiatric inpatient were approached by the Unit Manager. The Unit Manager then (a) provided the nurse with the letter of orientation to the study which briefly described the proposed 
investigation (see Appendix A), (b) ascertained their interest, (c) reassured nurses that they were not obligated to participate, and (d) obtained their verbal permission to be contacted by the researcher. Only after all of this was completed did I meet with each potential participant. At that time they were provided with a verbal and written explanation of the proposed study, an opportunity to ask questions, and an explanation of the need to audio-tape the interview (see Appendix B). The consent to participate was obtained after the explanation was completed and the informant's questions were answered. The consent included permission to tape record the interview (see Appendix C). As part of the consent process, participants were (a) provided with written details of the study, (b) informed of the risks and benefits of participating, (c) informed that their decision to participate in the interview was their own, (d) informed that they could refuse to answer questions or withdraw from the interview at any time without their work role being affected, and (d) given an assurance of confidentiality. The original signed consent forms have been secured by the researcher.

In order to protect subjects' right to privacy and confidentiality, all interviews were conducted in a private 
location at the hospital and all recorded data have been retained in a secure location. These data will be destroyed in seven years. The informants were assured that any report of this investigation would not identify them by name. Although they may recognize excerpts from their interview, this information would not be identifiable to others. The names of participants would appear only on the original consent form which has been secured by the researcher.

No direct risk to participants was anticipated nor did any known risk result from nurses' participation in this study. All participants were advised that, while they would not directly benefit from participation in the study, it was my hope that the study would enhance our understanding of the thoughts and feelings of nurses in situations involving the physical restraint of inpatients and the influence of these on nurses' decisions to restrain.

\section{Data Analysis strategies}

To bring order, structure, and meaning to the mass of data collected, analysis procedures involved data organization and data interpretation. These procedures followed the guidelines from Tesch (1990). 
Data organization techniques involved creating a data coding system which organized the mass of data for data interpretation (Tesch, 1990). The coding system in this investigation served as an organization device. Data interpretation strategies included the identification of themes and patterns from the data and the generation of the central study findings. Each of the data organization and interpretation strategies are described in further detail below.

Data organization:creating a coding system. The tape recorded interview data were transcribed following each interview. The accuracy of the transcription was determined by reviewing the transcript against the audio-taped interview. Once the accuracy of the transcript was established, the data were entered into the Ethnograph (Seidel, Kjolseth, \& Seymour, 1988), a qualitative data analysis software program. Following each interview, a contact summary sheet was completed. This entailed reviewing the interview transcript and the audiotaped interview by answering each of the questions on the contact summary sheet. A separate numbered file for hand coding was generated by the Ethnograph for each interview. The first three numbered files were read carefully, several times 
for the purpose of identifying distinct topics within the data. At this stage, there was no consideration for the actual content or substance of statements. The topics were abbreviated as codes and the codes were written next to appropriate segments of text. The coding of the first three interviews yielded 70 codes. The first three interviews were then re-coded. Although the codes were derived from the data themselves, the literature reviewed, the conceptual framework, and the research questions served as guides to conduct the recoding of the first three interviews. A master list of codes and the related descriptive wording for the identified topics were generated; the coded topics became the coded categories. The initial codes were applied to the remaining three interviews. As new codes appeared in the coding of each subsequent interview transcript, they were added to the master list of codes. As was expected, few new codes appeared following the coding of the first one third of interviews. All of the codes were reviewed and the infrequent codes eliminated while other codes were combined. This process resulted in 33 codes. Tesch indicates that it is customary to have between 25-50 codes. An alphabetical list of codes and their frequency was generated by the Ethnograph for each interview. 
To ensure reliability of the codes, the data were coded, and then re-coded several days later by the researcher. As well, the data were coded separately by the thesis supervisor. Inter-rater reliability was achieved by having the thesis supervisor separately code all of the interviews. The result of the inter-rater reliability was a yield of 31 codes. The coded interviews were reviewed in light of the 31 codes.

The final step in the organization of the data for interpretation was to assemble all the data belonging to one code in one place. Once this was achieved, the data were structured and ready for interpretation.

Data interpretation: identifying themes, patterns and central study findings. Topics were identified within the coded data for each interview and across interviews. Themes were generated from the topics. The themes were examined for how they were patterned within and across the interviews. Determining which themes and patterns were relevant to this investigation (since according to Tesch not all data are relevant) was achieved by examining them against the literature reviewed, the conceptual framework, and the research questions. Last, the themes and patterns judged as relevant were synthesized into the study findings. One 
overarching finding and four supporting themes were identified.

\section{Methodological Rigor}

The recommended measures of credibility, transferability, dependability, and confirmability were used in place of reliability and validity, employed in quantitative studies, to evaluate the trustworthiness of the research findings (Lincoln \& Guba, 1985).

Credibility. Credibility is described as the equivalent to internal validity (Lincoln \& Guba, 1985). According to Lincoln and Guba, evaluating credibility in naturalistic inquiry includes (a) understanding that reality is multiple and constructed, and (b) conducting the investigation in such a way that credible findings are probable. Several steps were taken in this investigation to ensure the basic quality of the data and thus establish the findings as credible. First, the researcher's perspective was made known so that it is evident that it is the subjects' experiences rather than the experience of the researcher which is described in the findings. Second, the interview process encouraged participants to speak of what was important to them, using their own language. Third, the researcher kept the research 
questions close at hand in both the data collection and data analysis to decrease bias stemming from the potential for the investigator to become enmeshed in the subjects' experience. Last, all data were coded and re-coded several days later by the researcher in addition to the data being coded separately by the thesis supervisor.

Transferability. Transferability, the counterpart to external validity, is the second criterion by which to evaluate qualitative research. Lincoln and Guba (1985) explain that the responsibility of judging applicability of findings to other subjects is the responsibility of the reader rather than of the researcher. It is a function of comparing the similarities between the context specific to the current investigation and that context to which findings are to be transferred. The researcher is responsible for providing "thick" descriptions about the time and context of the study so that readers have the information necessary to draw their own conclusions regarding transferability (Lincoln \& Guba, 1985). Information provided in this investigation which enable readers to make judgements about transferability include the socio-demographic data collected on each nurse interviewed, the description of the site, and details of the restraint 
situation. As well, details of the circumstances under which the study was conducted are described in the findings chapter. Dependability. Dependability in qualitative research is the criterion parallel to reliability. In qualitative research this is achieved by conducting an audit of the process by which the study was undertaken. Audit of the process refers to an assessment of the consistency and the stability of the approach used in the investigation (Lincoln \& Guba, 1985). In this investigation, consistency and stability of approach is evident in (a) the transcripts of the audio taped interviews, (b) the researcher memos written throughout the project which include my impressions of the interview and of the data, and (c) in the process of data analysis which is clearly detailed and which can be traced by another. All data, in their original form, will be kept for a seven year period and will be retrievable as required. Finally, the data analysis process was consistently applied to the data as it emerged.

Confirmability. Establishing confirmability involves determining if the findings and the interpretations are neutral and grounded in the data (Iincoln \& Guba, 1985). According to Lincoln and Guba, an assessment of neutrality is possible if any inferences drawn from the identified themes 
and patterns are judged as logical by readers of the findings. In this investigation, all data were analyzed by the same criteria. As well, the findings are supported with actual excerpts from the interviews.

In the next chapter, the study's findings are presented along with relevant excerpts from the interview data. 
CHAPTER 3

The Study's Findings

Description of the study Rarticipants, Restraint Incidents, and the study site

The research data were obtained from ethnographic interviews with six nurses working on a psychiatric inpatient unit of a community general hospital. The nurses were selected to participate in the study on the basis of their recent involvement in a restraint situation. The participants were all mature and experienced psychiatric nurses. All but one of the nurses reported having experienced an assault by a patient. All of the nurses had attended educational programs on the management of aggressive behaviour. The detailed characteristics of the sample of six nurses are presented in Table 1 .

The characteristics of the patients involved in the restraint situations were based on the nurses' descriptions of the patients during the interviews. The age, sex, and diagnoses of the patients involved in the incidents are presented in Appendix G. All of the patients had been restrained on at least one previous occasion during this or during other hospitalizations. 
Table 1

Socio-demographic Characteristics of the Nurses Interviewed

\begin{tabular}{|c|c|c|}
\hline CATEGORY & CHARACTERISTIC & FREQUEATCY \\
\hline AGE & $\begin{array}{l}42-45 \text { Years } \\
51-55 \text { Years } \\
\text { OVER } 56 \text { Years }\end{array}$ & $\begin{array}{l}2 \\
2 \\
2\end{array}$ \\
\hline SEX & $\begin{array}{l}\text { Female } \\
\text { Male }\end{array}$ & $\begin{array}{l}6 \\
0\end{array}$ \\
\hline $\begin{array}{l}\text { Years of Experience } \\
\text { in Psychiatric } \\
\text { nursing }\end{array}$ & $\begin{array}{c}10-15 \text { years } \\
\text { greater than } 15 \\
\text { years }\end{array}$ & 2 \\
\hline $\begin{array}{l}\text { History of a } \\
\text { Previous Assault }\end{array}$ & $\begin{array}{c}\text { Never assaulted } \\
\text { Assaulted by } \\
\text { Restrained Patient } \\
\text { Assaulted by a } \\
\text { Psychiatric Patient }\end{array}$ & 2 \\
\hline $\begin{array}{l}\text { Formal Training in } \\
\text { the Management of } \\
\text { Aggressive Behaviour }\end{array}$ & $\begin{array}{l}\text { Unit inservice } \\
\text { One day workshop } \\
\text { Two day workshop } \\
3 \text { or more days } \\
\text { workshop }\end{array}$ & $\begin{array}{l}5 \\
4 \\
1 \\
1\end{array}$ \\
\hline $\begin{array}{l}\text { Relationship to the } \\
\text { Patient at the Time } \\
\text { of the Restraint } \\
\text { Incident }\end{array}$ & $\begin{array}{l}\text { Assigned Nurse } \\
\text { Primary Nurse } \\
\text { Charge Nurse } \\
\text { Crisis Nurse } \\
\text { Admitting Nurse } \\
\text { Not Assigned to } \\
\text { Direct Care }\end{array}$ & $\begin{array}{l}1 \\
1 \\
1 \\
1 \\
1 \\
1\end{array}$ \\
\hline
\end{tabular}


In the six interviews, nurses discussed five different restraint episodes. All of these restraint episodes occurred on the evening shift except for one, which occurred on the day shift. Two of the incidents occurred in the same evening. The research site was an inpatient psychiatric unit located in a community general hospital. The hospital was a Schedule one Facility, which meant that patients certified under the Mental Health Act could be admitted. The security staff and porters employed by the hospital were also trained in the management of aggressive behaviour. They were often called upon to assist nursing staff with patients at risk of harming themselves or others.

The unit was a 30-bed, unlocked unit. The nursing staff were all registered nurses who practised within a primary nursing model. The unit had a policy which specified that all patients in four or five-point restraints had to be placed on constant observation. Constant observation involved a nurse keeping a restrained patient in constant view. The unit also had a policy in which a restraint bed, made up with five-point restraints (both arms, both legs, and waist), was always to be available for restraint situations. The availability of the restraint bed was intended to reduce the element of harm in 
restraint situations that may be caused by restraints not being readily available or by nurses having to struggle to quickly and accurately attach the restraints to a bed. Education in the management of aggressive behaviour was mandatory for the nurses and was provided on site, on an annual basis. As well, biweekly incident review meetings were held for the purpose of discussing recent situations involving restraint or seclusion.

\section{Overview of the Study Findings}

The analysis of nurses' thoughts and feelings, as described by the nurses in relation to a restraint situation, revealed that the restraint situation represented a decision dilemma. The decision dilemma entailed making a choice between risking harm to a patient, to other inpatients, and to staff and using physical restraints. The situation presented a dilemma because the nurses regarded both choices as representing unwelcome options. The nurses' descriptions of the restraint situations helped to explain why the restraint situations presented a decision dilemma for them. The essence of the decision dilemma was captured by four supporting themes which emerged from the nurses' expressions of their thoughts and feelings. The four themes were: (1) the framing of the 
situation: the potential for imminent harm, (2) the unsuccessful search for alternatives to physical restraints, (3) the conflicted nurse, and (4) the conditions of restraint. In the remainder of this chapter, these findings are described in detail by elaborating on each one of the four themes. Relevant excerpts from the interview transcripts are presented to support the findings.

\section{Elaboration of the study Findings}

Eraming of the Situation: The Potential for Imminent Harm

Knowledge of how the nurses described or framed the restraint situation elucidated what the decision dilemma entailed. The nurses perceived the restraint situation as a situation involving the potential for imminent harm to the patient, the other inpatients and in some instances to staff. All of the patients involved in the restraint situations were deemed to be at risk of harm. In three of the six interviews, both the other inpatients and the staff were perceived to be at risk of imminent harm and in one interview, the environment was at risk of being damaged.

The nurses determined, early in the restraint situation, that a potential for imminent harm existed. They also 
concluded that this potential for imminent harm continued to exist as the situation evolved up to and including the application of restraints. Each of the nurses' actions was directed by their view of the situation as one of potential imminent harm. While the interview transcripts provide explicit statements by the nurses affirming their perception of imminent harm, the affect expressed in the interviews also conveyed the intensity of their feelings.

The nurses determined that a potential for imminent harm existed based on the patient's behaviour at the time. In addition to the patient's immediate behaviour, the nurses also had in their thoughts an awareness of the patient's behaviour within the past few days on the unit or the patient's behaviour during previous admissions to the unit. The nurses also were faced with patients who were harming themselves, or who were threatening to harm themselves, the environment, the other patients, or staff. They perceived that the patients, the environment, and the staff needed protection from harm. All of the nurses described the importance of keeping patients and staff safe; this was interpreted as nurses' sense of duty to protect. The excerpts below contain 
examples from the restraint situations wherein nurses arrived at the determination of harm.

In interview 001, the restraint episode described occurred in the emergency department. The nurse was assessing the patient for possible admission when she returned to the interview room to find the following:

The light had been turned off and he was standing in the corner and he had put his belt around his, the belt was hanging from one of the ceiling rafters and he was standing on the chair. When I went back in the room he said "I'm suicidal and you have to admit me to hospital," at which point he stuck his head in the loop. Now the loop went kind of under his chin, around the top of his head. It wasn't anywhere near his windpipe and I wasn't sure at that point if he was just going to dislocate his jaw or what kind of damage he could do. As I called for help, the ceiling crashed in and then the tiles came down.

This nurse's thoughts at the time also described her perception of the potential for imminent harm in this situation. She said: 
He clearly indicated, and he was impulsive, had the ability to act out and the ability to pull down the ceiling and create quite a bit of chaos in the emergency department... He is unpredictable and angry and I'm sure he was angry enough over his discharge to go out and perhaps endanger somebody else. Furthermore she described the need to protect the patient, the department and the staff:

He went into restraints for his own protection and to keep the emergency room from being wrecked... He had to be put in a cubicle that had all kinds of equipment so he had to go into 5-point restraints....He was in there [restraints] to protect himself and to protect the staff down there and to protect the department.

The patient being restrained, as well as the staff, were deemed to be at risk of potential imminent harm. The nurse concluded this on the basis of her consideration of the patient's behaviour in the emergency department, his past violent behaviour, as well as the physical set up of the emergency room. 
The situation described in interview 002 involved a Eemale patient in her $30^{\prime} \mathrm{s}$ who was diagnosed with Multiple Personality Disorder. She had slashed open an old abdominal wound. The nurse involved was the primary nurse and had a longstanding relationship with the patient. The nurse was involved in assisting with the suturing of another inpatient and came out to find the following:

We found her in the bathroom and she had slashed her abdomen open. Then we had to have her sutured, a second suturing. As we did it she starting switching [personalities] a lot.

The nurse's thoughts at the time were focused on what she knew about this patient's past history of self-harm, on her past behaviour, and on her relationship with this patient. It is these thoughts along with the act of self-harm that played a role in this nurse framing the situation as one of a potential for imminent harm. The nurse described the patient's potential for self-harm:

She has this potential, I don't know if it is true or not, but she has multiple, query multiple personalities and then she switches and then selfmutilates badly, very badly. 
The nurse believed the patient was at continued risk of harm after the slashing. By virtue of the primary nurse relationship, the nurse had extensive knowledge of the patient's history. This history played a prominent role in the framing of the situation as did the patient's behaviour that evening.

In interview 003, the restraint situation involved an 18 year old female patient who at the time of the situation was an involuntary patient. The patient expressed an intent to kill herself by leaving the unit and jumping off a nearby bridge. This threat to kill herself was a reaction to the patient learning from another patient that the nurses were overheard to have said that she acted out only as a means of gaining attention. The nurse described the situation as follows :

She wanted to leave, she is on a form [Certificate of Involuntary Admission] and she said when I asked her why, she said to kill herself. She said she was going to go out and jump off the bridge. So I tried to reason with her, I tried to take her into a private room for some time out, just to sit quietly. I offered her medication. She refused and then she became, she just suddenly became 
combative.... She had gotten out as far as the elevators and then she just went ballistic. She started kicking, punching and trying to bite the staff. She was knocking her head against the wall. We got her down to the floor and she was flailing around....As soon as they become combative, you don't have a choice because you can't contain them, we are not a locked unit.

The nurses' view or framing of the situation was based on the patient's expressed intent to harm herself. Specifically, the patient was not responding to the nurse's interventions, and the patient was at high risk for self-harm given that the means which the patient threatened to use was available (a bridge was located just outside the hospital). Furthermore, this situation was perceived to create a potential for danger to the other inpatients because of their reactions to the restraint of this patient. As a result, the other inpatients were also perceived to be at risk of imminent harm. The nurse explained:

She was screaming so loudly and disturbingly that there were three other patients outside her room where we had her that were peeking in the door. And one of them started just flipping out. She is a 
paranoid schizophrenic personality and seeing this and listening to this just escalates her. So we had these three other patients because she was screaming... There were those patients outside just flipping out.

The patient involved in the restraint situation described in interview 004 was the same patient that was involved in the situation described in interview 001 . He was involved in a subsequent incident following the one in the emergency department as he was being admitted to the inpatient unit. The incident occurred when he was being returned to four-point restraints after the restraints had been removed to allow the patient to change into hospital pyjamas. The nurse described the situation as follows:

He resisted and he fought and it took three security guards and about six porters and as many nurses as were available....He was screaming through all of this.... He was fighting and resisting and being forced into bed while two nurses worked at fixing the restraints. And then finally they got that organized and he fought being put into restraints....He has the potential to do damage to 
himself or to someone else. He could hurt someone, there is no question. It took all that staff to keep him controlled.

The nurse who described this incident determined that the risk of imminent harm, in this situation, extended beyond the patient being restrained to include the unit as a whole and the staff involved in the restraining. The nurse's view of the situation described in interview 004 was determined on the basis of the patient's behaviour while being re-restrained on the unit, his previous behaviour that same night in the emergency room, and the potential danger to other inpatients. The nurse in interview 005 was assisting in the restraint of the same inpatient described in interview 003 . This nurse described, at length, why she viewed the situation as potentially harmful to other inpatients who reacted to the initial restraint episode:

What concerned me most about this whole episode was the fact that there were a number of younger patients who sort of spent all their time together and I was afraid of the effect of all of this on them and on the rest of the floor... Everybody seemed to be getting very agitated, the whole floor 
was getting out of control and I was concerned we would have more of a crisis. As it turned out, we did have more of a crisis.... I was frightened for the whole floor... I felt scared that the safety of the unit.... I felt there was a real possibility that it could get out of control.... We had very few patients that night who were cool, calm and collected.

The potential for imminent harm for this nurse encompassed the risk of imminent harm to the patient being restrained, as well as the risk of imminent harm to the other inpatients.

In interview 006, the nurse's determination of imminent harm in the situation described was based on the patient's involuntary status, her resistance to being admitted to hospital, and the nurse's knowledge of the patient's past behaviour. She described the situation as follows:

The patient came in with her husband after being seen by her psychiatrist and she was quite hesitant to be admitted. She wanted to leave.... She was resistant regarding this admission.... She was quite restless and she was having disorganized thinking-addressing me as Doctor. Sometimes she would mention my name and other 
times she would forget me and ask where she was, so there was fluctuation in her memory.... She had poor eye contact, holding her husband's arms and saying she doesn't belong in here.... She was offered medication and she refused to take it... She presented as an elopement [leaving the hospital without permission] risk.... I was thinking that she would be loud and really would be pretty aggressive. As I've said I know the patient really well and she had the tendency to do that. She can be dismissive and can be very furious... She has the potential to escalate.

A difference in this situation, as compared to the others, was that the potential for imminent harm extended to the nurse. The nurse's perception of potential risk to herself was based, in part, on the fact that this patient had been aggressive toward her in past admissions. In addition to the patient's present and past behaviour, this nurse perceived herself to be at risk of harm because of the conditions under which the situation occurred. The nurse described how she did not have any other unit nurses to assist her as they were busy with other unit activities. Instead, the only colleagues available to assist her were a psychiatrist, an occupational 
therapist, and a unit secretary, none of whom had received training in the management of aggressive behaviour nor did their responsibilities include dealing with restraint situations. The nurse did have porters assisting her but even though they were trained, she wished for, and expected to have, nurses to assist her. This nurse also described the importance to her of having the "restraint" bed available: You know I felt really quite uptight because in cases like this there should really be, it would be easier if the restraint bed had been made.... I was upset with regard to that [the unmade restraint bed] and with the staff, with no other staff to help me because they are busy with their own patients. Then it made it a little bit worse for me because I had to do it with a secretary and the psychiatrist, they are not used to doing this.

The framing of the situation: the potential for imminent harm, emerged as a key element in the nurses' decision dilemma. In all of the above restraint situations, the patient being restrained was deemed to be at risk of imminent harm. Understanding the nurses' view of the restraint situation as 
one involving the potential for imminent harm provides insights into the nature of the decision made by the nurse. The Unsuccessful Search for Alternatives to Physical Restraints

The second major theme, the unsuccessful search for alternatives to physical restraints described another aspect of the restraint situation that exposed the situation as a decision dilemma. In interviews 001,002, 003 and 006, the nurses discussed the alternatives to restraints that they either tried or considered trying during the restraint situation. The other two nurses interviewed were not in a position to seek alternatives to physical restraint. In interview 004, the nurse did not look for alternatives because she restrained the patient based on a doctor's order. As well, she herself felt there was no other option but to restrain because of the degree of aggression displayed by the patient. This nurse did, however, make a reference to seeking alternatives that was prompted by the incident but not specifically related to the patient involved. This will be discussed following the examples from the other interviews. The nurse in interview 005 was assisting the other nurses in a restraint situation, did not have and explicit opportunity to 
search for alternatives to restraint, and was not the nurse making the decision to restrain.

The nurses' thoughts revealed the process by which they arrived at restraints as the option for managing the perceived harm. Alternatives to physical restraints were evaluated with regard to whether or not sufficient protection of the patient could be achieved relative to the degree of harm perceived. The alternatives that were considered were those available at the site. Specifically, the unit had a waist restraint which enabled the nurses to apply anywhere from a one-point restraint to five-point restraints. The site also had seclusion rooms available for use.

The nurse in interview 001 thought that the patient was not pleased with her approach to his request for admission, because she did not immediately agree to have him admitted. In her opinion, he was not getting what he wanted. She also perceived him as someone who was determined to get into hospital. After his suicide attempt in the emergency room, the nurse put him into five-point restraints. She stated, however, that the waist restraint alone (which gave the patient greater range of movement than did limb restraints) is what she would have preferred to use. She ruled out this option because it 
would not have effectively protected the patient or the environment from the perceived degree of harm. She had medicated the patient but this intervention alone was not deemed to be sufficient to protect him, the environment and the staff from further harm, so restraints were also applied. She explained:

Often all we use is the waist restraint. But because he had to be put in a cubicle that had all kinds of equipment that they use in the emergency department in there he had to go in five-point [restraint]. He was left in restraints because he was unpredictable and angry.

In interview 002 the nurse revealed her thoughts and feelings, as she described her struggle between using restraints and using seclusion. The nurse took into account the specific risk of harm in the situation, her knowledge of the patient's preference for restraints, her memory of the patient's attempts to harm herself while in seclusion, and her desire to maintain what little trust the patient had in her. The nurse described what led her to choose restraints:

I did not want to restrain. But I know with her it's a bit different to restraining other patients 
because she feels safe in restraints so it doesn't have to be a force. She very easily goes into it. She'd rather you, she feels very safe.... She had expressed how frightened she is. And I find that I just can't imagine, myself, how I would feel if I had been raped all my life by my family and been locked in the cellar in the room like she has been and then somebody does the same to me.... I know it is very scary for her.... I think she is not a person that has much trust and she sort of trusts me. And I feel a loss quite often when I have to do something, if I have to seclude her, or I would be feeling that I would be breaking her trust.

The nurse described why seclusion would not have not been sufficient to protect this patient:

She sort of welcomes the feeling of safety but if you also put her in a room by herself or in seclusion, she goes crazy or loses it... She is a person that can't be secluded because she, or she sometimes when she becomes secluded, it brings back a lot of memories. And then she goes crazy, she really does lose it... I've put her in seclusion before and I think that's why lately I 
haven't because it's only recently that she told me just how frightened she gets. But last time I tried to seclude her she tried to choke herself and she tied her things tightly around her neck.... I wonder that seclusion is safe enough for her, I don't think that's for her.... I think, I feel instinctively if we put her in seclusion, it will be wrong.

The nurse spoke of wanting to have this patient on constant care (being under continuous observation but not restrained) prior to this incident. She believed that constant care was the most effective intervention for her. She described why she could not use this option:

You are supposed to stop those constant cares because we just don't have the finances. And she should be on constant care.

The nurse in interview 003 provided a detailed description of the interventions she tried in an effort to calm the patient prior to using the restraints. These efforts were unfortunately unsuccessful, which led the nurse to the option of restraints. This nurse provided a description of how the situation evolved to the point of restraint and her initial effort to try less restrictive alternatives. In 
the description, the dynamic nature of the decision process in the restraint situation is illustrated:

We were having a one-to-one and I thought we had a good rapport.... I explained to her very calmly and quietly when she first said she was going to leave, I said you're on a certificate, you're an involuntary patient and you can't leave.... I told her what her Iimitations were, what her rights were as far as being involuntary, but she still chose to try to leave.... She said she was going to go out and jump off the bridge so I tried to reason with her, I tried to take her into a private room for some time out, just to sit quietly, offered her medication. She refused and then she became, she just suddenly became combative. I was holding her by the arm but gently you know, I had just sort of looped my arm in her arm and was trying to walk her back, she had gotten out as far as the elevators, and then she went ballistic.... I had pretty well used up those sort of approaches and then right after that she became combative and I was right into, you know, the restraint bed is the next step, only until the 
chemical restraints kick in, which is the medication.

The nurse also described her thoughts at the time regarding the ineffectiveness of seclusion to protect this patient from harm:

We do have seclusion rooms that lock but seeing her banging her head against the wall, seclusion room wouldn't have worked because she would have been banging herself and possibly putting her head through the glass. She was going to bang her head so the seclusion room wasn't an option. She would have hurt herself in the seclusion room.

The patient described in interview 006 was an involuntary patient who was resisting being admitted to hospital. The nurse described how she first offered medication to the patient, giving the patient a choice of the route by which to take it. She had hoped that by taking the medication the patient would have been more amenable to being admitted. She had also thought of using restraints but hoped to use the less restrictive waist restraint. However, the waist restraint did not fit the patient. The patient refused medication so the nurse felt her only option was to apply four-point restraints. 
The patient did take the medication but restraints were also applied. The restraints were taken off after a short while because the patient did not resist being put into them. The nurse's thoughts were:

You know, she was not resistant to that [restraints] so I said, you know, maybe I'll see, maybe she doesn't really need a five-point. Plus the waist restraint wouldn't fit her. I was looking to putting her only on the waist restraint but it wouldn't fit her.... So that's why I said okay, so just put her in leg restraints and one arm....Had the waist restraint fitted on her, then that would be fine.... I know that leaving the right [arm] restrained, knowing that she has the potential to escalate, that you know if I leave the other limb free she was okay. So there was no point really putting her in five-point.

The nurse in interview 004 did not discuss alternative measures to restraint for this patient as she immediately deemed that physical restraints were needed. The decision to restrain was based on a physician's order to use restraints, and on the degree of aggression displayed by the patient, both 
on the unit and earlier that evening in the emergency department. Nevertheless, this interview highlighted how the search for alternatives also occurred following the specific restraint situation. At the same time, her experience shed light on one of the barriers to seeking alternatives to restraint. Based on the events of this evening, as well as on the events of the past week, this nurse made a decision to arrange for an additional nurse for the evening shift the next day. She believed that by adding one more nurse to the next evening shift, the staff would have had more time to speak with patients and as a result, similar incidents might be avoided. She felt that patients needed more attention from the nurses and that this attention could possibly help to avert restraint situations. However, the nurse was reprimanded for making this decision. She said:

Our supervisors and coordinators don't really understand what's going on here because they're not really in touch with, they don't come in and watch what happens or what we're dealing with. And then they chew us out the next day because we hired the constant care and I hired an extra nurse for saturday evening and I was censored [reprimanded] for that. We had two or three 
patients who really you couldn't count on and I resent [being censored] because they had a good evening and the unit was more settled Sunday and Monday because I think possibly they [patients] had some time to talk to the nurses, so it is sort of a trade off.

The nurses that were in a position to seek alternatives to physical restraint, did so. In all cases, according to the nurses, no other alternatives that would have protected the patient against the harm, as effectively as restraints, were available. Under the circumstances, the nurses perceived physical restraints to be the best available option.

The first two themes, the framing of the situation: the potential for imminent harm and the unsuccessful search for alternatives to physical restraint described what the decision dilemma entailed. The nurses perceived that patients, themselves, and others were at risk of imminent harm. Also, they perceived that there were no alternatives to restraint available that would have been effective in the situation. The third theme, the conflicted nurse, further elaborated on the restraint situation as a decision dilemma. 
The conflicted Nurse

The first two themes elucidated what the decision dilemma entailed. The next major theme, the conflicted nurse, captured the conflict related to restraint use which contributed to the decision dilemma. The nurses were in conflict as a result of (a) being in a situation in which patients and others were perceived to be at risk of imminent harm, and having to choose from two equally unwelcomed options--risking harm and physical restraints, (b) believing that it was their duty to protect but having to choose an unwelcomed intervention--restraints-which was viewed as representing a failure to protect, and (c) the personal and emotional impact of restraint use on the nurse. The nurses' conflict further clarified why restraint use represented a decision dilemma as illustrated in the following interview excerpts.

Risk of harm: an unacceptable option. The analysis of the nurse's descriptions of the restraint situations and their expressed thoughts and feelings explicated why risking harm to patients and others was not acceptable. The fact that risking harm was unacceptable partially explains why the nurses were in conflict. Nurses perceived patients and staff to be at risk of imminent harm and harm to a patient or others conflicted 
with their sense of duty, as well as their professional, legal, and ethical responsibility to protect patients. The nurses felt they had to act in a manner consistent with their sense of duty to protect patients, themselves, and others as described in the following excerpts.

The nurse's thoughts in the following excerpt, from interview 001, reflect her sense of duty to protect:

When things get out of hand you have to protect yourself first because if you don't you are no good to anyone else and you certainly can't protect the other patients... you take whatever measures you can to protect patients.

The same nurse also described her sense of helplessness, and by inference, her desire to protect:

He was hanging there and so actually I was afraid at that point that he was going to hang himself.... Well I felt sort of helpless for a few seconds there because I was not, I'm not large enough or strong enough to have been able to lift him. So that if the noose had been around his neck I would not have been strong enough. And at that point I was not sure where it was, he had just kicked the chair out and 
was hanging there. Fortunately, the ceiling crashed down.... You always, think you know, what if the person had the noose in the right position and what if it really was someone who was intent on killing themselves? So there is a helplessness at that stage that I would not be able to lift him back up there. It takes time to kind of get the chair back up. I would have nothing on me to cut the belt. In interview 002, the nurse expressed strong feelings about keeping all patients safe, not just the restrained patients :

I would like to know that the most important stuff is what we handle. And keeping the place safe for others is important.

This nurse also referred explicitly to her feelings of frustration over her inability to prevent the situation. The expectation that she should or could have prevented the situation suggested that neither harm to others nor restraints were welcome options. She said:

I think there is sometimes a feeling of failure although I know that it is impossible to be with them the whole time. It's just, how could I have 
prevented it? Why didn't I prevent it? And maybe I should have gone more with my gut feeling.... I know that there is still the feeling of maybe a little bit of guilt that maybe I hadn't done enough....Feeling impotent at some times. You know that I'm damned if I do and damned if I don't and I'm not going to help in any case. I think I get angry when I feel impotent, angry with myself.... feel anger and helplessness that she had done so well, stopped cutting her abdomen for a long time... I think maybe angry at my own inability to be really useful although I know I'm not God. Similarly, in the incident described in interview 003 , the nurse accounts for her intent to contain this patient by referring to her desire to protect her from self-harm. She talked about her goal to protect in the broader purpose of promoting health and life. In light of this nurse's goal to protect, risking harm was inferred as being unacceptable. She said:

You want to put them in an area away from other patients, a safe area.....All I could think about at the time, all I can think of is prevention, all I can 
think about at the time is stopping her from doing it.... It's an ugly situation. It's ugly, but what is the alternative? Like her being strapped down or being splattered on the street under the bridge? What would you rather do?... Unfortunately it does become part of my job because you have to weigh out what the best way of controlling the situation is. And protecting the patient from themselves that's the lesser of the evil... You know we promote health, we promote life, we're doing this to protect.

In the example from interview 004, the nurse described her sense of the duty to protect in terms of her responsibility to keep patients safe:

It's the job, it's part of the job, this is what I do and I've done it many times so that it has to be done in order to keep this person safe.... It's just that we keep the place safe... We know that he is safe and other people are... The primary concern is to keep each patient safe. Similarly, in interview 005, the nurse described her concern for everyone's safety. She also described feeling scared that the situation could get out of control. 
I felt scared that the safety of the unit even though I wasn't in charge. I guess I'm in charge enough to feel that the whole unit is everybody's responsibility and I just I did not want to see it get out of control. And I felt there was a real possibility that it could and I felt very scared about that.

Risking harm to patients or others was unacceptable because harm to patients contradicts nurses' sense of duty to protect patients and themselves.

Physical restraints: an unwelcome option. The unsuccessful search for alternatives required the nurses to resort to the only other available option in the situation, that of physical restraints. The nurses' conflict was, in part, a consequence of restraints being unwelcome.

The unwelcome nature of physical restraints was described by the nurses in terms of restraint use being synonymous with a Eailure to protect, the negative impact of restraint situations on the entire inpatient population, the nurses' view of restraints as a last resort intervention, and the sense of dread associated with the use of restraints. The use of restraints was not much more welcome an option than was risking harm to a patient. 
The nurse in interview 002 questioned what she may have done differently to have prevented the patient from harming herself. She identified feeling a sense of failure to protect because she had not prevented the situation. Restraints were unwelcome because for this nurse their use represented a failure to protect. These thoughts also reflected self-blame: I think, in a way, although the feeling is relief, it's a feeling of how could I have prevented her from getting so far? Is there anything I could have done that would have made me stop to get her from that state that actually necessitated the restraints? I think that is sometimes a feeling of failure although I know that it is impossible, I can't be with them the whole time. It's just, "how could I have prevented it? Why didn't I prevent it?" And "maybe I should have gone more with my gut Eeelings?"

This nurse described, in interview 003, the negative impact of the situation on other inpatients as she discussed the importance of resolving restraint incidents quickly:

We resolved it very quickly which has, that's the way it has to be. You can't go back and forth and 
drag it out. It escalates. You deal with it for the sake of the other patients... We try to convey to the other patients, "Don't feel threatened, she won't threaten you, because the situation is under control."

The nurse in interview 004 also spoke of how restraint situations have a negative impact on other inpatients in what she described as the "aftermath" or the upset on the unit. She also described the negative impact of restraint situations on patient care in general:

It's [the situation] upsetting to other patients.... There is always an aftermath on the unit. The unit is more unsettled and there are people upset after something like this. So you are dealing with the fallout with other patients too.... It's at the back of my mind to make sure other patients understand that they're okay and that this isn't going to happen to them... The restraining took staff away from those patients who wanted attention and resent when they don't get it. And they see this person getting the attention of 10 
people, regardless of what kind of attention it is, they feel they're being neglected.

The nurse in interview 005 expressed her awareness of the negative impact of the restraint situation on the other inpatients :

What concerned me most about this whole episode was the fact that there were a number of younger patients who sort of spent all their time together and I was afraid of the effect of all this on them and on the rest of the floor.... I didn't want them upset by this but obviously they were very upset by this.... I was frightened for the whole floor. The nurse in the following excerpt, from interview 001 , discussed her view of restraints as a last resort intervention because of the potential for someone to get hurt:

I've been involved in a number of restraint situations over the years, we try very hard to avoid that for practical reasons, because people don't want to get hurt. So it's a method of last resort.

In interview 003, the nurse described feeling a sense of dread associated with the use of restraints and expressed her 
thoughts about restraints as a last resort intervention. She said :

Kind of a sense of dread because restraints is the last thing you want to do. You really wish that, you know, they could comply with the other alternatives, take the medication, calm down, take some time out.... It's ugly, we hate getting physical with people.

The emotional impact of restraint use on nurses. The emotional impact of restraint use described by the nurses further elaborated why the option of restraints was regarded as unwelcome, as well as further elucidating the nurses' conflict.

In the excerpt below, the nurse in interview 001

discussed the personal impact of her repeated involvement in restraint situations:

There is the physical, there is the emotional, and there's that after something like that you're wondering what the hell are you doing working in a place like this? Like really.... go on vacation to visit my family and they are all what you would call ordinary people and I couldn't tell them what I do. 
They wouldn't believe it and if they did believe it, I would be afraid of what they thought was wrong with me for working in this setting... Very often it's quite a while after an incident before you feel anything about it. You go into some other mode of operating and you just do it and afterwards like the incident here, you go down and have dinner as though nothing happened. And then, an hour later, feel all shaky inside like your legs are rubber, this is a delayed reaction to it.

The nurse in interview 003 also described the emotional impact of restraint use on her:

It's draining, like usually after an episode like that you are drained, wiped out... It can be emotionally draining. You feel tapped out when you leave after a night like that....It's like being in a MASH, you know, it's like being in a war zone.

This nurse continued to describe the extent of the emotional impact on her as she described feeling unable to care for the patient on a subsequent shift:

It changes the relationship, I can't, right now, I won't take her as a patient because right now I 
don't feel that I could be therapeutic with her because I'm angry at her.

The nurse in interview 004 described the personal and emotional cost of restraint use:

I come away from a situation like that and don't look at people. You sort of go off into yourself for awhile. And I am not sure why that is... I wonder quite honestly why I go on working here.... You know it's unbelievable that you go to work and have to face that sort of thing. I mean, it is almost more than you can fathom what you're doing. It's sort of hard to accept. The nurse in interview 005 described her fear of being hurt in a restraint situation when the staff were busy dealing with other patients. She also described the impact of the situation on herself and on the other nurses:

Oh Lord, I felt very alone because there wasn't anybody there. They were all in the room, you know.... It's very unnerving and it's very unsettling and I think what unsettled me most of all was that I was concerned by these others that were around her lthe patient being restrained].... We were talking about how awful, you know, we're shaking and we feel awful. 
The thoughts and feelings of all the nurses interviewed described aspects related to restraint use that contributed to the conflict they experienced. They were faced with having to choose between risking harm to patients and others or using physical restraints. In addition to this, the emotional impact of restraint use on nurses contributed to the conflict. The reason restraint use represented a decision dilemma was elucidated in the theme: the conflicted nurse. Conditions of Restraint

The conditions of restraint constituted the fourth theme. In this theme were captured the contextual circumstances under which the decision dilemma occurred. The conditions described refer to the facility-specific factors which the nurses identified as contributing to the decision dilemma. The conditions identified by the nurses were (a) the composition of the inpatient population at the time, (b) the facility policy of having all restrained patients on constant care, and (c) the attitude of management and physicians at the facility. The composition of the inpatient population at the time. The nurses described the atmosphere of the inpatient unit at the time of the restraint situations in terms of patient behaviours and the diagnoses of some of the other inpatients. 
The patient behaviours and the milieu created by the composition of inpatients at the time influenced nurses' perception of the risk of harm. The composition of inpatients at the time and their behaviours challenged the nurses' ability to protect patients. The restraint situations described in interviews 001 to 005 inclusive all occurred within the same week, some on the same evening. The nurses described the unit as being unsettled as a result of the behaviours of several of the inpatients. Several patients had been in restraints over the course of the week and the range of patient behaviours included: patients who had harmed themselves while on the unit, patients who required sutures for self-inflicted injuries, patients who threatened to harm themselves, and a patient who harmed herself in response to another patient being restrained. Similar activities were occurring while the nurse in interview 006 was involved in a restraint situation which contributed to this nurse's perception of personally being at risk.

The nurse in interview 003 provided this description of the behaviours of the other inpatients while a restraint situation was in progress: 
We were actually having a bad night. That night we had another patient down the hall carving herself up with a razor blade and a third patient who re-opened an old self-inflicted laceration...then there were those patients outside [the room of the patient being restrained] just flipping out...we were just trying to get our stuff done and look after our other patients... we were busy, you know, trying to put out fires, trying to calm everybody else that was upset by it [restraining] too.

She further described the composition of the inpatient population as follows:

You know there is an element on the unit right now of personality disorders that are quite disruptive. And of course there is a clique of them and she lthe patient being restrained] is quite comfortable. It's like high school antics you know, kind of stuff. She is in with that crowd which is unfortunate... Now this fellow she chums around with is a terrible influence on her.

The nurse in interview 005 described the reaction of the other inpatients to a restraint situation. Her description 
reflects her perception of the increased potential for harm which was related to staff not being available to assist her. The staff were still dealing with the initial restraint episode which provoked the reactions in the other inpatients. She described the following:

I was outside the room and I was trying to keep two schizophrenic patients calmed down and that got to be really difficult. I couldn't keep them away from the door. I couldn't move them into the front lounge... one of the patients she did a lot of socializing with was head banging in the front lounge...the whole floor was getting out of control...another schizophrenic patient kept going on and on that we were abusing this patient and we should know our limitations and she'd been abused. And this went on and on and on. Now there was another patient sitting down the hall and yelled to the other one to shut up. And she just used a lot of foul language and she said she couldn't handle hearing what the patient was yelling at the nurse... in the meantime there were these guys in the front and this other guy kept circling and circling 
and circling and was very angry about the fact that she was being restrained... He was the main instigator of the patient [being restrained] acting out...the other guy in front, he started crying and wailing and going on and on.

In interview 006, it was the nurse who felt unsafe in the situation due to the lack of help from the nursing staff who were busy with other activities on the unit. The lack of nursing staff to assist contributed to her feelings of anger in the situation and to her perception of the situation as potentially harmful to herself:

The staff were really busy. The unit was really busy that day too... I think we had a patient who was very loud at the time and she was yakking at her nurse. And then there was another one who wanted to be accompanied downstairs who was also a very difficult patient at the time... forgot, it was an ECT [electroconvulsive therapy] day and if it's an ECT day we are pretty busy. Plus, at the time, the unit was really chaotic having, you know, we had a few acting out patients at the time. 
The facility's constant care policy. The facility policy of having all restrained patients on constant care was another condition of restraint which contributed to the decision dilemma in the restraint situation. The policy did not deter the use of restraints but was a consideration in the nurses' decision to use restraints. The nurses described their Erustration with being unable to predict when an extra nurse would be needed to provide the constant care and that it was not always possible to locate an extra nurse. Furthermore, a patient in restraint requiring constant care would mean that the patient assignment would then have to be adjusted and the nurses felt that the heavier workload that resulted took them away from their other patients. At the same time the nurses also made reference to feeling pressured by management to reduce the use of constant care because of the cost associated with it. Nevertheless, while these "external" concerns contributed to the nurses not welcoming restraints as an option, it did not prevent them from using restraints. The nurse in interview 001 described the impact of the constant care policy in terms of the increased workload of staff that results from the unpredictable need for a nurse for the constant care. The policy did not deter her from using 
restraints but it was a factor when she considered restraints as an option. The nurse referred to the constant care policy in the following passage:

Patients in restraints go on constant observation and we lose a staff off the floor until we can call and get somebody to come in. But we are still losing someone for an hour or an hour and a half. And sometime there is nobody available to come in and in that case we just kind of rotate through. So it makes for a lot heavier workload for everybody when we put someone in restraints.

This nurse, during interview 004, echoed similar sentiments to those expressed above. She described the impact of the constant care policy:

Putting that young man in restraints, we suddenly had to provide a constant care nurse for him and that meant pulling a nurse from her five patients. So that presents a problem for others on the unit. The attitude of management and physicians. This facilityrelated factor contributed to the emotional reactions of nurses during the restraint situations as well as contributing to the emotional impact of restraint use on nurses. 
The nurse in interview 004 described the frustration she felt in response to the lack of support from the psychiatrists, particularly when she had to call them during a restraint situation or call to get a medical doctor to see a patient. It was her perception that management and physicians were of the attitude that it was acceptable, because it is part of a nurse's job, for a nurse to get hurt, but it was not acceptable for a physician to get hurt.

We've seen doctors, while we've had an incident on the unit, run and one doctor was hit by a patient once and he raised a tremendous ruckus about it. And yet we get hit and they all say "Well, it's just part of your job." so there is a great undercurrent of resentment against the doctors and the attitudes of our superiors who have told us it's part of our job and we resent that I don't think it should happen.... It adds to the feeling of frustration and adds to the feeling of resentment which wouldn't be so bad really because restraining is part of the job. But when you add all of this other stuff, you know, not having adequate orders and not being able to get medical help when you need it. 
While the nurse was dealing with the restraint situation described in interview 005, she had the following encounter with a psychiatrist as she went back to the nursing station to call for additional help:

Most of the time, he's [referring to the psychiatrist] pretty supportive but the way he came across that night was not supportive... [he says to her] "You've got to keep control of these patients" and I said "Dr., you know, like we would PRN [medicate as necessaryl", he kept telling us to PRN everybody, we [did] prn everybody, you know, it's just the patients we have.

The facility-specific factors, which constituted the theme the conditions of restraint, in turn contributed to the decision dilemma by influencing the nurses' perception of the potential for imminent harm. The nurses identified unitrelated facility factors which contributed to the decision dilemma.

\section{Summary of the Findings}

This chapter presents evidence derived from the thoughts and feelings expressed by nurses which demonstrated that the restraint situation represented a decision dilemma for them. 
Two themes, the framing of the situation: the potential for imminent harm, and the unsuccessful search for alternatives to physical restraint, clarified what the decision dilemma entailed. The third theme, the conflicted nurse, captured the nurses' conflict which resulted from their being in a situation in which there existed a potential for imminent harm and the available options were regarded as unwelcome. Also contributing to the conflict was the emotional impact restraint use had on nurses. Consequently, the reasons why the restraint situation represented a decision dilemma were revealed. The conditions of restraint, the fourth theme, constituted the circumstances under which restraints were used. The conditions influenced the decision dilemma by contributing to the potential for harm in the restraint situation and by dictating which alternatives were available for nurses to choose from.

The next chapter provides a discussion of the study findings in relation to the existing literature and the conceptual framework guiding the study. 
CHAPTER 4

Discussion of the Findings

\section{Overview}

This ethnographic qualitative study was undertaken to learn more about nurses' thoughts and feelings regarding restraint use, and to understand the influence these thoughts and feelings may have on nurses' decisions to restrain. The analysis of six nurses' thoughts and feelings revealed that restraint use represented a decision dilemma for them. This decision dilemma is constituted by the dimensions captured in the four themes of the study. The themes are: the framing of the situation: the potential for imminent harm, the unsuccessful search for alternatives to physical restraints, the conflicted nurse, and the conditions of restraint.

Restraint use in this study was described by nurses as a situation in which patients and others were at risk of imminent harm. Based on this perception, nurses seek interventions to manage the perceived harm. As a result, nurses were faced with having to choose between two unwelcome options--risking harm or using restraints. The nurses experienced conflict because of the unwelcome nature of these options and because these options also contradict nurses' 
professional, legal, ethical, and personal responsibility to protect patients. As well, nurses' thoughts and feelings influenced every aspect of decision making, the data collected, the options considered and the decision to restrain. Finally, the conditions of restraint reflect the circumstances in which restraints were used. The study findings are further discussed below according to the emergent themes and in relation to the existing literature and the conceptual framework guiding the study.

Emergent Themes and the Existing Literature

The decision dilemma and the dimensions which constitute the decision dilemma comprise a description of restraint use by nurses that has not yet been captured in the literature. In general, restraint use has been linked with patient-related factors such as age, sex, and diagnosis (Betemps et al., 1993; Carpenter et al., 1988; Mattson \& Sacks, 1978; Okin, 1985; Phillips \& Nasr, 1983; Sheridan et al., 1990; Soloff, 1978, 1979; Soloff et al., 1985; Way \& Banks, 1990); facilityrelated factors (Katz \& Kirkland, 1990; Morrison, 1990); and staff-related factors (DiFabio, 1981; Dubin, 1989; Felthous, 1984, Gallop \& Wynn, 1987; Roper and Anderson, 1991). Gleaned from these studies is an understanding that restraints have 
been used most often with young males with a diagnosis of schizophrenia, that unit organizational structure and unit ideologies influenced the incidence of restraint use, and that restrictive measures are used by staff in response to their perception of patient behaviour as violent. The decision dilemma and its constituents captured in this study extends the findings from previous research by uncovering the complexity of restraint use and by enhancing the current understanding of why nurses use restraints.

The theme, the framing of the situation the potential for imminent harm, reflected nurses' view of the restraint situation and revealed what the decision dilemma entailed for nurses. The findings related to this theme extend the current literature dealing with staff-related influences and restraint use.

The harm perceived in the restraint situation was described by the nurses in a broader sense than is described in the current Iiterature. In different studies, the perception of patient behaviour as violent has been linked to the use of restrictive measures like restraints (Coulson et al., 1985, 1986; DiFabio, 1981; Dubin, 1989; Felthous, 1984; Lion \& Pasternak, 1973; Okin, 1985; Roper \& Anderson, 1991). 
Dubin (1989), Felthous (1984), and Lion and Pasternak (1973), each hypothesized that psychiatrists were frightened by patients who had the potential to become violent and responded to these countertransference reactions by using restrictive measures. Nurses have also been reported to experience fear and anxiety in response to potentially violent patients (Coulson et al., 1985; Difabio, 1981; Gallop \& Wynn, 1987). Nurses' emotional reactions have been speculated as influencing the use of restrictive measures (Coulson et al., 1985, 1986; DiFabio, 1981; Okin, 1985; Roper \& Anderson, 1991). The perception of the potential for imminent harm described in this study was about the risk cf harm to patients and others. Based on this, restraints were used not as a response to the fear of harm to the practitioner but in response to a perception of harm that extended beyond the practitioner to include the patients and others. In only one of the interviews did the nurse explicitly describe her personal fear of injury, in addition to the potential for harm to the patient, as motivating her use of restraints. The nurses' perception of imminent harm, in part, establishes the decision dilemma and provides the basis for a more comprehensive understanding of why restraints were used. 
The theme, the unsuccessful search for alternatives to physical restraint, further illustrated what the decision dilemma entailed. The nurses did not have many options to choose from and as a consequence they were left with making a choice between two equally unwelcome options--risking harm or using restraints. Previous studies have not asked questions which would generate a description of restraint use in which nurses' search for alternatives would be discussed. Thus, it is difficult to discuss this study finding in relation to the existing literature. The nurses' search for alternatives to physical restraint captured nurses' attempts to manage the perceived harm, illustrating that restraints were not nurses' first choice of intervention. The fact that there were few options to choose from and that the search was unsuccessful also supports restraint use as a decision dilemma and elucidates the complexity of restraint use.

The next theme, the conflicted nurse, elucidated another reason restraint use represented a decision dilemma. The conflict resulted from nurses having to choose between equally unwelcome options and which contrasted with nurses' professional, legal, ethical, and personal responsibility to protect. Compounding the conflict were nurses' emotional 
reactions to restraint use. There are no published studies in which nurses' conflict in the restraint situation has been described or identified. In contrast to the experience of conflict described in this study are the findings of Morrison (1990) and Muir-Cochrane (1996) in which nurses expressed feeling comfortable using restrictive measures, such as restraint and seclusion. In Morrison's study, conflict did not emerge as a finding. This may be because nurses were rewarded for controlling patient behaviour even if the control was achieved through the use of restraints. It is not known whether nurses experienced conflict in relation to restraint use, since their emotional reactions to restraint use were not addressed in Morrison's study.

Similarly, in the qualitative study conducted by MuirCochrane (1996), in which nurses' perception of the role of seclusion on a locked unit were investigated, nurses reported feeling comfortable using seclusion because control of patient behaviour was paramount to achieving a therapeutic environment. As well, seclusion was a means of ensuring safety and safety was integral to maintaining a therapeutic environment. Nurses' emotional reactions to seclusion were not a focus of the study by Muir-Cochrane. Her descriptions of 
nurses' use of restrictive measures are in contrast to the descriptions provided by the nurses interviewed in this study. The theme, the conflicted nurse, captured why restraints were used by these nurses and conveys the opposite sentiment toward the use of restrictive measures to that which was reflected in the studies by Morrison and Muir-Cochrane. The conflict which emerged in this study highlights that restraint use can be problematic for nurses. The difference in nurses' reactions between this study and those by Morrison and Muir-Cochrane warrants further exploration.

In this study, nurses' emotional reactions to restraint use further elucidated why restraints were regarded as unwelcome, as well compounded the experience of conflict. In only one study (DiFabio, 1981) were nurses specifically asked to discuss their emotional reactions to restraint use. DiFabio described 21 categories of emotional responses which included anxiety, hopelessness, frustration and fear. Other studies have focused on either nurses' emotional reactions to difficult patients (Gallop \& Wynn, 1987) or on nurses' emotional reactions to violence (Roper \& Anderson, 1991). Gallop and Wynn identified clusters of difficult patients. One of these clusters included patients who frequently and 
unpredictably exhibited behaviours such as screaming, swearing, blood letting, and threatening. Nurses' responses to these behaviours were described as intense and personal. The emotional responses of nurses to violence, identified by Roper and Anderson, included increased tension, hopelessness, helplessness and countertransference. Even though the emotional reactions described by Gallop and Wynn and Roper and Anderson were not related to restraint use, the nurses in this study similarly reported feelings of fear, anger, frustration, and helplessness. These emotions were inspired by patient behaviours exhibited in the restraint situation, and were a response to the perceived risk of harm. Thus, the findings of this study complement those of DiFabio, Gallop and Wynn, and Roper and Anderson.

Finally, the conditions of restraint influenced the nurses' perception of the potential for imminent harm, the choice of alternatives, their experience of conflict in the restraint situation and, ultimately, the decision dilemma. The conditions of restraint reflect the site-specific factors which influenced restraint use in this setting. Katz and Kirkland (1990) reported that unit organizational structures influenced the level of violence on a unit and subsequently 
the use of restrictive measures. Morrison (1990) reported that the unit's philosophy was one in which control of patient behaviour was valued and this ideology influenced restraint use on the unit. While the facility factors in this study were different from those described by Katz and Kirkland and by Morrison, they did influence restraint use. Describing the conditions of restraint enriches the understanding of restraint use as a decision dilemma.

Emergent Themes and Conceptual Eramework

The findings of this study are consistent with Etzioni's (1992) approach to decision making. In his descriptive approach, Etzioni indicated that inferences and facts are part of decision making and choices are dominated by values and emotions. Furthermore, he believes that people are "governed by normative-affective factors" (p. 90). These normativeaffective factors not only influence every aspect of decision making, they also provide the context in which decisions are made. In this decision making model, processing of information is secondary to the influence of the normative-affective factors.

Consistent with Etzioni's (1992) approach, nurses' drew on normative commitments and affective involvements when 
making the decision to restrain. The normative-affective factors influenced the information collected by the nurses, the nurses' appraisal of that information, and the decision to restrain. This influence is evident in the nurses' thoughts and feelings and in each of the study themes.

The view of the restraint situation reflected in the theme the framing of the situation: the potential for imminent harm, was arrived at on the basis of the emotions inspired in the nurse in response to the patient behaviours, the nurses' sense of duty to protect, and the patient behaviours. In the interviews, nurses described the patient behaviours at the time of the incident, the patients' past behaviours, the feelings generated by these behaviours, and their commitment to protect patients. The duty to protect is not simply a personal preference, it is a value which originates from nurses' professional, legal, ethical, and personal responsibility to protect patients. Influencing the nurses' view of the restraint situation were the nurses' emotions (affective involvements) and the nurses' sense of duty (normative commitment) to protect patients. The information gathered about the patients' behaviour was secondary to the influence of these normative-affective factors. 
In the theme, the unsuccessful search for alternatives, nurses described the options they considered and their appraisal of these options. Influencing the nurses' search for alternatives was their commitment to protect patients. Nurses evaluated the available options in terms of their effectiveness to protect the patient from the perceived degree of harm. The value of protecting patients guided the search for alternatives. The search, however, was unsuccessful. The options considered would not enable nurses to act in a way that was consistent with their sense of duty to protect.

Nurses found themselves having to choose between two unwelcome options--risking harm or using restraints. In the theme, the conflicted nurse, nurses' thoughts and feelings revealed the underlying values and emotions which influenced them to regard these options as unwelcome. Risking harm was unwelcome because harm contradicted with nurses' sense of duty to protect. The view of restraints as unwelcome was influenced by nurses' affective involvements. Using restraints inspired a sense of dread, fear and anxiety at the prospect of not being able to protect, and fear of being harmed. Restraint use also had a lasting emotional impact on the nurse. These normativeaffective factors draw out the conflict experienced by nurses 
in restraint situations. This conflict may not have been acknowledged if a rational choice approach was utilized. If individuals are thought to be self-interested and act independently of others, there might be little reason to feel conflicted since the choice to restrain would have been motivated by the individual's self-interest.

In the theme, the conditions of restraint, there is further support for Etzioni's (1992) approach. The nurses spoke of being pressured to reduce costs associated with restraint use. In the restraint situation, the nurses' commitment to protect patients guided the decision, not the desire to be efficient and reduce costs, which might be the perceived motivation in a rational choice approach.

The description of restraint use in this study also supports Zey's (1992) critique of the assumptions underlying rational choice theories. The use of restraints was not motivated by nurses' self-interest or their personal preferences. As well, organizational factors also influenced restraint use. If nurses were in deed motivated by selfinterest and personal preference, they may have restrained simply to protect themselves and not considered the need to protect the unit or others. Furthermore, if nurses were 
motivated by self-interest, how is their sense of duty to protect others accounted for.

One final challenge to rational choice theories, is the view of the organization. The decision to restrain in this study was made in the context of an organization with authority structures, goals, and parameters for decision making (as was evident in the theme the conditions of restraint). Nurses engaged in information gathering, appraisal of the available options, consideration of organizational factors, and made the decision to restrain. Decision making in the restraint situation was influenced by normative-affective factors.

Evident in every dimension of the decision dilemma is reflected the influence of normative-affective factors on the information gathered by the nurses, the appraisal of the options available, and the decision to restrain. Nurses' decisions to restrain are understood differently when the influence of normative-affective factors in decision making were acknowledged. 
CHAPTER 5

Summary, Limitations, and Recommendations

\section{Summary}

In this ethnographic qualitative study nurses' thoughts and feelings revealed that restraint use represented a decision dilemma for them. This conclusion is drawn from the analysis of data collected Erom ethnographic interviews with six nurses from a 30-bed inpatient psychiatric unit in a community general hospital. The ethnographic interview was designed to encourage explicit descriptions of nurses' thoughts and feelings in relation to an actual and recent restraint situation in which they participated. A crucial aspect of the interview process was that nurses were able to recall and discuss their thoughts and feelings and describe the restraint episode using their own words.

The decision dilemma is supported by the four study themes. The themes constitute a description of the dimensions of the decision dilemma. The decision dilemma existed as a result of the nurses' framing of the restraint situation as one involving the potential for imminent harm to patients and others. In view of this framing, nurses sought interventions by which to effectively manage the harm. The search for 
interventions resulted in nurses having to choose between risking harm or using restraints. These options were both unwelcome and placed the nurses in conflict with their professional, legal, and ethical responsibility to protect patients. Using restraints also conflicted with nurses' personal sense of duty to protect because restraints represented a failure to protect. The conditions of restraint further contributed to the decision dilemma.

\section{Limitations and Challenges}

There was one limitation in this investigation. The study may be limited because it was conducted in a single site with a smail homogeneous sample. It was not possible to obtain the desired sample size of $10-12$ as the incidence of restraint use during the study period fell below the hospital's reported average.

There was a challenge associated with the study interest in capturing nurses' feelings about restraint use. It was difficult for nurses to speak of their feelings rather than just the objective description of the events. In order to stimulate the expression of feelings, it was necessary for the interviewer to prompt nurses to return to their feelings and to use probes to guide them to do so. It may be that the 
traumatic nature of the restraint experience impedes the expression of feelings. It may also be that nurses are not socialized to speak of their feelings. In the end, the challenge of stimulating the expression of feelings was overcome by the researcher's use of the techniques associated with the three essential criteria of the ethnographic interview. The researcher kept the interview guide and the research questions at hand during each of the interviews. The audio-tapes and the interview transcripts were reviewed within a day or two of the interview also with the research questions and interview guide close at hand. In completing the contact summary sheets, particular attention was paid to nurses' expressions of their feelings drawing the researcher's attention to the importance of using the techniques for ethnographic interviewing.

Recommendations for Research. Theory and clinical practice

Research. Learning about restraint use in psychiatry is an ongoing endeavour which necessitates further research. To this end, replicating this study with a larger and more diverse sample and adding participant observation as a mode of data collection, may contribute further knowledge about restraint use in the psychiatric setting. Also, studies which 
focus on patients' thoughts and feelings regarding restraint use may contribute further to the current understanding of the continued use of restraints. A study such as this could also provide insights into patients' experiences with restraint use.

Theory. It seems that descriptive approaches to decision making are helpful in understanding restraint use. It would be useful to further examine nurses' decisions to restrain in light of Etzioni's (1992) approach. As well, further study of restraint use in light of other decision making theories may contribute additional insights into this practice.

clinical practice. Several of the nurses interviewed for this study commented on the therapeutic value of the interview. They perceived the interview as similar to a debriefing and found it therapeutic because they could express their thoughts and feelings without fear of reprisal. It seems important to structure a process for debriefing that would provide this opportunity for nurses (or any staff) involved in restraint situations. A key to effective debriefing may be the opportunity to express thoughts and feelings about a specific situation soon after it happens and without fear that a negative consequence would result from the honest expression 
of thoughts and feelings. A debriefing as such may enable nurses to recognize and deal with the personal and emotional impact of restraint use.

Another implication for clinical practice would be the modification of the management of aggressive behaviour education program. This education should include an opportunity for nurses to discuss their thoughts and feelings about restraints and their repeated involvement in these situations. Role plays which incorporate aspects of actual restraint situations including the emotions associated with restraint use may prove to be an effective teaching technique. Findings from this study may be used as the basis for developing case studies which could be used to socialize nurses who are new to psychiatry or to stimulate the discussion of thoughts and feelings related to restraint use.

\section{Conclusion}

The use of restraints in the psychiatric setting is more complex than has been conveyed in prior research. It is complex because restraint use represents a decision dilema for nurses. Restraint situations involve a broad risk, not only to patients, but to staff and to the physical envirnoment. As well, the options available for dealing with 
the risk are regarded by nurses as equally unwelcome. Moreover, these options conflict with nurses' sense of duty to protect and their professional, legal, and ethical responsibilty to protect patients. In response to the restraint situation, and compounding the nurses' conflict, nurses experience feelings of fear, anger, anxiety and helplessness. The conditions of restraint further complicate restraint use by influencing nurses' perception of risk of harm, by contributing to the conflict, and by dictating which alternatives were available to nurses. As illuminated in this study, nurses' thoughts and feelings about restraint use concur with Etzioni's (1992) proposition that decision making is influenced by normative-affective factors. The normativeaffective factors influencing nurses' decisions to restrain included nurses' sense of duty to protect patients, nurses' fear that harm would result, nurses' fear of personal harm, and nurses' sense of helplessness to protect patients. Continued research is required to confirm the description of restraint use as a decision dilemma and to formally test the influence of normative-affective factors in nurses' decisions to use physical restraints in the psychiatric setting. 


\section{References}

Baron, J. (1994). Thinking and deciding (2nd ed.).

Cambridge: Cambridge University Press.

Betemps, E.J., Somoza, E., \& Bouncher, C.R. (1993).

Hospital characteristics, diagnoses, and staff reasons

associated with use of seclusion and restraint. Hespital and Community Psychiatry, 44(4), 367-371.

Burns, N. \& Grove, K.S. (1993). The Practice of nursing research conduct, critique, \& utilization (2nd ed.).

Philadelphia: W.B. Saunders Company.

Carpenter, M.D., Hannon, V.R., McCleery, G. , \&

Wanderling, J.A. (1988). Variations in seclusion and restraint practices by hospital location. Hospitai and Community

Rsychiatry, $39(4), 418-423$.

Coulson, D.B., Allen, J.G., Coyne, L. Deering, D., Jehl, N., Kearns, W. \& Spohn, H. (1985). Patterns of staff perception of difficult patients in a long-term psychiatric hospital. Hospital and Community Psychiatry, 36 (2), 168-172.

Coulson, D.B., Allen, J.G., Coyne, L. Deering, D., Jehl, N., Kearns, W. \& Spohn, H. (1986). Profiles of difficult psychiatric hospital patients. Hespital and Community Psychiatry, 37(7), 720-724. 
Crenshaw, W., B., \& Francis, P.S. (1995). A national survey on seclusion and restraint in state psychiatric hospitals. Psychiatric Services,46, 1026-1031.

Difabio, S. (1981). Nurses' reactions to restraining patients. American Journal of Nursing, 81(5), 973-975.

Dubin, W. (1989). The role of fantasies, countertransference, and psychological defenses in patient violence. Hospital and Community Psychiatry, $40(12), 1280$ 1283.

Etzioni, A. (1992). Normative-affective factors: Toward a new decision making model. In M. Zey (ed.). Decision making alternatives to rational choice models (pp. 89-111). Newbury Park: Sage Publications.

Felthous, A. (1984). Preventing assaults on a psychiatric inpatient ward. Hespital and Community Psychiatry, 35 (12), $1223-1226$

Gallop, R., \& Wynn, F. (1987). The difficult inpatient: Identification and response by staff. Canadian Journal of Rsychiatry, 32, 211-215.

Government of ontario. (1988). Mental Health Act. Ontario: Ministry of the Attorney General. 
Government of Ontario. (1996). Mental Health_Act. Ontario: Ministry of the Attorney General.

Hammersley, M., \& Atkinson, P. (1983). Ethnography Rrinciples in Practice. London: Tavistock Publications. Johnson, B., Martin, M., Guha, M., \& Montgomery, P (1995). The experience of thought-disordered individuals preceding an aggressive incident. (Submitted for publication) Katz, P., \& Kirkland, F.R. (1990). Violence and social structure on mental hospital wards. Rsychiatry, 53, 262-277. Lincoln, Y., \& Guba, E. (1985). Naturalistic Inouiry. Beverly Hills: Sage Publications.

Lion, F., \& Pasternak, S. (1973). Countertransference reactions to violent patients. American Journal of Psychiatry. $130(2), 207-210$.

Miles, M., B. \& Huberman, (1994). Oualitative Data Analysis. Thousand Oaks: Sage Publications.

Mattson, M. \& Sacks, M. (1978). Seclusion: Uses and complications. American Journal of Psychiatry 135(10), 12101212 .

Morrison, E.F. (1990). The tradition of toughness: a study of nonprofessional nursing care in psychiatric settings. IMAGE: Journal of Nursing Scholarship. $22(1), 32-38$. 
Morrison, E.F. (1993). A comparison of perceptions of aggression and violence by psychiatric nurses. International Journal of Nursing Studies, 30, 261-268.

Muir-Cochrane, E. (1996). An investigation into nurses' perception of secluding patients on closed psychiatric wards. Journal of Advanced Nursing 23, 555-563.

Okin, R.L. (1985). Variation among state hospitals in use of seclusion and restraint. Hospital and Community Psychiatry, $36(6), 648-652$.

Phillips, P., \& Nasr, S. (1983). Seclusion and restraint and prediction of violence. American Journal of Psychiatry. $140(2), 229-232$.

Ray, N., K. \& Rappaport, M., E. (1995). Use of restraint and seclusion in psychiatric settings in New York State. Psychiatric Services, 46, 1032-1037.

Roper, J.M., \& Anderson, N.L., (1991). The interactional dynamics of violence, Part 1: an acute psychiatric ward. Archives of Psychiatric Nursing, V, 209-215.

Sandelowski, M. (1995). Sample size in qualitative research. Research in Nursing and Health, 18, 179-183. 
Seidel, J.V., Kjolseth, R., Seymour, E. (1998). The ethnograph: a user's quide. Corvallis, OR: Qvalis Research Associates.

Sheridan, M., Henrion, R., Robinson, L., \& Baxter, V. (1990). Precipitants of violence in a psychiatric inpatient setting. Hospital and Community Psychiatry, 4I(7), 776-780.

Soloff, P.H. (1978). Behavioral precipitants of restraint in the modern milieu. Comprehensive Psychiatry, 12(2), 179184.

Soloff, P.H. (1979). Physical restraint and the nonpsychotic patient: clinical and legal perspectives. The Journal of Clinical Psychiatry, 32, 302-305.

Soloff, P.H. (1983). Seclusion and restraint. In J. Lion \&W. Reid (Eds.), Assaults within psychiatric facilities (pp. 241-264). Orlando: Grune \& Stratton, Inc.

Soloff, P.H., Gutheil, T.G., \& Wexler, D. (1985). Seclusion and Restraint in 1985: a review and update. Hespital and Community Psychiatry, 36(6), 652-675. Spradley, J.P. (1979) . Ethnegraphic interviewing. New York: Holt, Rinehart and Winston. 
Steele, R.I. (1993). Staff attitudes toward seclusion and restraint: Anything new? Rerspectives in Psychiatric Care, $29(3), 23-28$

Tesch, R. (1990). Qualitative Research Analysis Types \& Software Teols. New York: The Falmer Press.

Vidich, A., J., \& Lyman, S., M. (1994). Qualitative methods their history in sociology and anthropology. In N.R. Denzin \& Y.S. Lincoln (editors), Handbook of Qualitative Research, (pp. 23-59). London: Sage Publications.

Way, B., \& Banks, S. (1990). Use of seclusion and restraint in public psychiatric hospitals: patient characteristics and facility effects. Hespital and community Psychiatry,4I(1)，75-79.

Yarmesch, M., \& Sheafor, M. (1984). The decision to restrain. Geriatric Nursing, 5, 242-244.

Zey, M. (ed). (1992). Decision Making Alternatives to Rational Choice Models. Newbury Park: Sage Publications, Inc. 
Appendix A

Letter of Orientation for Potential Study Participants

Sandy Marangos-Frost is a registered nurse and a Master of Science student of the Department of Nursing science at the University of Toronto. Her thesis supervisor is Dr. Donna Wells, assistant Professor at the Department of Nursing Science at the University of Toronto. Ms. Marangos-Frost is conducting a study that explores nurses' thoughts and feelings in situations involving the restraint of psychiatric inpatients.

Your participation in the study would involve a one hour interview discussing a restraint situation in which your recently participated, as well as an additional one-half hour to explain the interview process and to collect sociodemographic information on each interviewee. I am asking if you would be interested in meeting Sandy to discuss the study with her. Meeting with her does not mean you are consenting to participate. You are under no obligation to meet with Sandy or to participate and your decision has not bearing on your employment.

Would you agree to the release of your name and telephone number to Ms. Marangos-Frost so that she can discuss the study with you in further detail. 
Appendix B

Explanation of Study to Potential Study Participants

My name is Sandy Marangos-Frost. I am a Master of Science student of the Department of Nursing Science at the University of Toronto. I am conducting my master's research under the supervision of $\mathrm{Dr}$. Donna Wells, assistant professor at the Department of Nursing Science at the University of Toronto. The purpose of the study is to learn about the thoughts and feelings nurses experience in situations involving the physical restraint of a psychiatric inpatient and the influence these thoughts and feelings may have on nurses. decisions to use physical restraints. The decision to use restraints is not being evaluated.

The study has been approved by a human subjects review Committee of the Office of Research Services at the University of Toronto, the research committee of this hospital and by your unit manager. You are being asked to participate in this study because of your recent involvement in a restraint situation. It is important that I understand nurses' thoughts and feelings experienced in actual restraint situations rather than discussing nurses' general opinions regarding restraint use. If you agree to participate, it would mean being interviewed by me and asked to discuss with me a specific restraint situation in your own words, as well as the thoughts and feelings you recall experiencing in the situation. It is important to describe the situation in as much detail as possible and in your own language. Interviews will be arranged at your earliest convenience following a situation in which you participated in the decision to use physical restraints on a patient admitted to the psychiatric inpatient unit. The interview will be conducted in a private location at the hospital during your working hours. It is expected that the interview will require approximately one hour of your time. An additional 30 minutes is required to allow me to explain the interview process and to obtain some demographic data about yourself. This sociodemographic data is required so that I may describe the study participants in the written report of the study. This enables readers of the findings to determine if this study site is similar to their own and subsequently, if the findings may be applicable to their site. 
Appendix B (continued)

Your name or any identifying information will not appear in any report of the results. There is no direct benefit to you if you participate nor are there any consequences for refusing to participate. Your participation is voluntary and you may withdraw at any point in the study.

It is essential that I obtain a verbatim account of the interview so that your own words and descriptions, rather than my interpretations of your responses, are accurately captured. To ensure this, each interview will be tape recorded with the consent of the participant.

If you would like more information regarding the study or have any concerns about it please contact me at 284-8131 extension 4104 or my thesis supervisor at 978-2854.

If you agree to be interviewed, then I would like to arrange a time for us to do so and to have you sign the consent form. 
Appendix C

Interview Consent Form

I, consent to take part in the (name of participant)

masters study conducted by Sandy Marangos-Frost. I have read and understood the "Explanation of study to Potential Participants". I understand that the purpose of the study is to understand nurses' thoughts and feelings in restraint situations and how these may influence the decision to use physical restraints.

I understand that I will be interviewed for approximately one hour and will be asked to provide some sociodemographic information about myself. My name will not appear on any report of the study nor will my colleagues have access to any information that I contribute.

My decision to restrain is not being evaluated. There is no direct benefit from participating in this study nor any risk if I choose to withdraw. I understand that I may withdraw at any time and refuse to answer any of the interview questions or provide any sociodemographic data.

I understand the interview will be tape recorded and I consent to this. 


\section{Appendix D \\ Socio-Demographic Information \\ (Nurses)}

Code :

Age: 20-25

41-45

$46-50$

$26-30$

$31-35$

$36-40$

$51-55$

-

older $\begin{aligned} & 36-40 \\ & \text { than } \overline{56}\end{aligned}$

Gender :

F

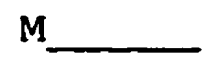

Years in Psychiatry

$0-3$ $3-6$ $6-10$ $10-15$

Greater than 15

History of Assault (i.e. grab, strike):

By the Restrained Patient No

By any Psychiatric Inpatient No

Yes

Yes

Formal Training in Management of Aggressive Behaviour No

Yes: Unit Inservice /hospital orientation

One-day workshop

Two-day workshop

workshop longer than 3 days

Relationship to the Restrained Patient at the time of the restraint episode: (Check one)

Assigned Nurse:

Primary Therapist:

Not assigned to Direct care:

Other: 
Appendix $\mathbf{E}$

Introduction

\section{Interview Guide}

My name is Sandy Marangos-Frost. I would like to thank you for volunteering to be interviewed for this study. Before we begin the interview, let me first briefly explain the purpose of the study, as well as what you can expect from this interview. The purpose of the study is to learn about nurses' thoughts and feelings experienced in situations involving the restraint of a psychiatric inpatient. This interview will enable me to learn about nurses decisions to restrain patients from nurses' descriptions of their experiences in a recent restraint situation. During the interview, I will be asking questions which will guide your descriptions of the restraint episode but there will not be any mutual exchange of information between us as the interview is different from a friendly conversation. I would like you to think of me as someone who is not familiar with restraint situations. Although I have been involved in physically restraining psychiatric inpatients, the circumstances under which they occurred were different. When answering questions, please use words, phrases or expressions that you would find yourself using with a colleague.

I would like you to complete an information sheet with some personal data about yourself. This information will enable me to give some details about the sample so readers of the research can judge the findings as applicable to their setting.

Finally, as discussed in the consent process, the interview will be tape recorded to ensure that a verbatim account of the interview is captured.

\section{Ethnographic Questions:}

Descriptive Questions:

1. Describe the most recent restraint situation in which you were involved as if you were speaking to a nurse you work with. 
Appendix E (continued)

2. Describe the thoughts and feelings your recall experiencing during the most recent rrestraint situation in which you participated.

3. Describe the feelings you think other nurses may experience in restraint situations.

Structured Questions:

4. Walk me through the situation as it occurred.

5. What stood out in this situation for you?

6. Describe the behaviour and actions of the patient in the situation prior to the application of the restraints.

Contrast Questions:

8. Is that how other nurses would describe that?

9. Can you use that same word in a different sentence?

(Spradley, 1979) 
Appendix F: Contact Summary Sheet

Contact Type:

Interview :

Contact date:
Phone :

Today's date:

1. What were the main issues or themes that struck you in this contact?

2. Summarize the information gathered with each question. (Write out each question on the audio-tape).

3. Is there anything that struck you as interesting, important or illuminating in this contact?

4. What needs to be considered for the next contact?

5. Which of the research questions, or conceptual framework did the interview bear on most centrally? 
Appendix G

Characteristics of the Restrained Patients and Incident Information

\begin{tabular}{|c|c|c|c|c|c|c|}
\hline Characteriotic & Int 001 & Int 002 & Int 003 & Int 004 & Int 005 & Int 006 \\
\hline AGE & 23 & $25-30$ & 18 & 23 & 18 & 50 \\
\hline $\mathbf{S E X}$ & M & F & $\mathrm{F}$ & M & $\mathrm{F}$ & F \\
\hline DIAGNOSIS & $\begin{array}{l}\text { Per- } \\
\text { sonality } \\
\text { Disorder }\end{array}$ & $\begin{array}{l}\text { multiple } \\
\text { per- } \\
\text { sonality } \\
\text { disorder }\end{array}$ & $\begin{array}{l}\text { per- } \\
\text { sonality } \\
\text { disorder } \\
\text { adjust- } \\
\text { ment } \\
\text { disorder }\end{array}$ & $\begin{array}{l}\text { per- } \\
\text { sonality } \\
\text { disorder }\end{array}$ & $\begin{array}{l}\text { per- } \\
\text { sonality } \\
\text { disorder }\end{array}$ & $\begin{array}{l}\text { schizo- } \\
\text { phrenia }\end{array}$ \\
\hline $\begin{array}{l}\text { HISTORY OF } \\
\text { SIMIIAR } \\
\text { INCIDEITS } \\
\text { YES }\end{array}$ & $\mathrm{x}$ & $\mathrm{x}$ & $\mathrm{x}$ & $\mathrm{x}$ & $\mathrm{x}$ & $\mathrm{x}$ \\
\hline $\begin{array}{c}\text { INCIDENT } \\
\text { INEORMATION: } \\
\text { TIME OF DAY }\end{array}$ & $\begin{array}{c}\text { EVENING } \\
\text { SHIFT }\end{array}$ & $\begin{array}{l}\text { EVENING } \\
\text { SHIFT }\end{array}$ & $\begin{array}{l}\text { EVENING } \\
\text { SHIFT } \\
\text { SAME } \\
\text { EVENING } \\
\text { AS } 002\end{array}$ & $\begin{array}{c}\text { EVENING } \\
\text { SHIFT } \\
\text { SAME } \\
\text { EVENING } \\
\text { AS } 001\end{array}$ & $\begin{array}{c}\text { EVENING } \\
\text { SHIET }\end{array}$ & $\begin{array}{c}\text { DAY } \\
\text { SHIFT }\end{array}$ \\
\hline \#STAFF INUOLVSD & $\begin{array}{l}\text { nurses } \\
\text { porters } \\
\text { police }\end{array}$ & $\begin{array}{c}7-8 \\
\text { total } \\
\text { nurses } \\
\text { and } \\
\text { porters }\end{array}$ & $\begin{array}{c}8 \\
\text { nurses } \\
\text { and } \\
\text { porters }\end{array}$ & $\begin{array}{c}10 \\
\text { nurses } \\
\text { porters } \\
\text { security }\end{array}$ & $\begin{array}{l}8 \\
\text { nurses } \\
\text { and } \\
\text { porters }\end{array}$ & $\begin{array}{c}6-7 \\
\text { nurse } \\
\text { M.D. } \\
O . T \\
\text { Unit } \\
\text { sec- } \\
\text { retary } \\
\text { porters }\end{array}$ \\
\hline
\end{tabular}



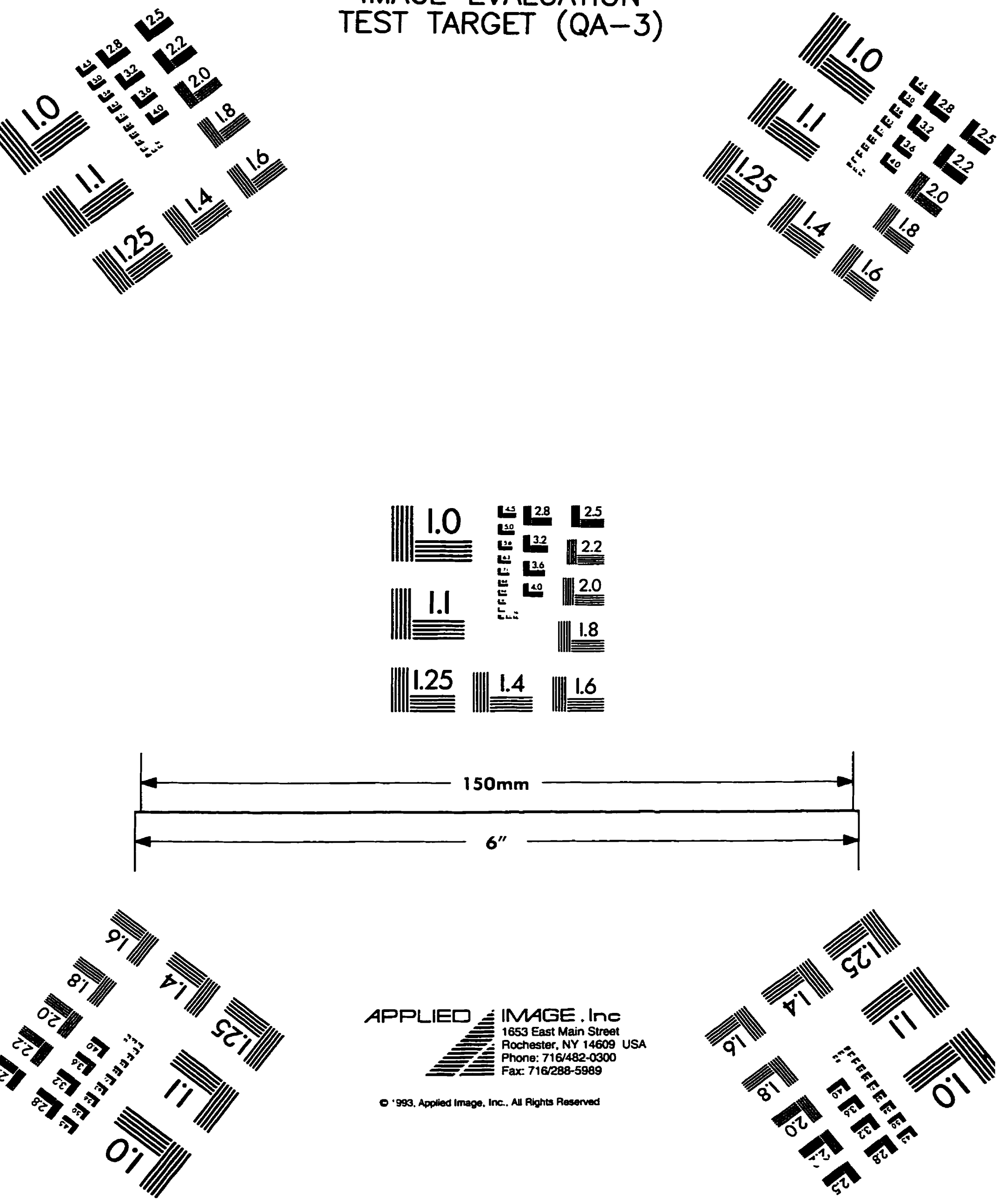

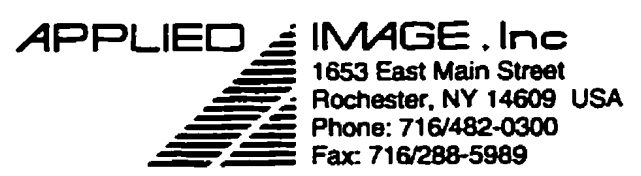

- 993. Applied Image. Inc. All Aights Resonved

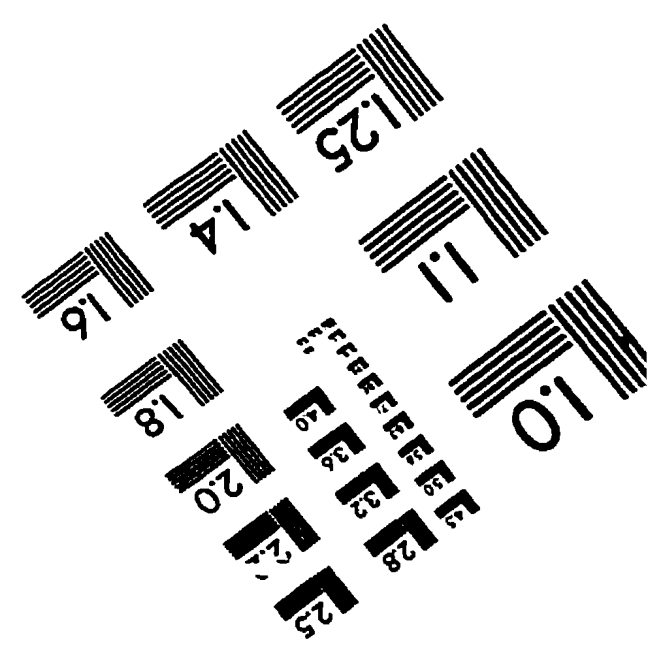

